\title{
Investigation of the Effect of Climate Change on Extreme Precipitation: Capital Ankara Case
}

\author{
Sertac ORUC ${ }^{1}$ \\ Ismail YUCEL ${ }^{2}$ \\ Aysen YILMAZ ${ }^{3}$
}

\begin{abstract}
This study examines the potential impacts of climate change on extreme precipitation. Rainfall analysis with stationary and nonstationary approach for observed and future conditions is performed for (1950-2015 period) observed data of 5, 10, 15, 30 minutes and 1 , 2, 3, 6 hour and projections (2015-2098 period) of 10, 15 minutes and 1, 6 hour for Ankara province, Turkey. Daily projections are disaggregated to finer scales, 5 minutes storm durations, then five minutes time series aggregated to the storm durations that are subject of interest. Nonstationary Generalized Extreme Value (GEV) models and stationary GEV models for observed and future data are obtained. Nonstationary model results are in general exhibited smaller return level values with respect to stationary model results of each storm duration for observed data driven model results. Considering the projected data driven model results; on average nonstationary models produce mostly lower return levels for mid and longer return periods for all storm durations and return periods except one hour storm duration. Depending on the models and Representative Concentration Pathways (RCP), there are different results for the future extreme rainfall input; yet all results indicate a decreasing extreme trend.
\end{abstract}

Keywords: Climate change, storm water, nonstationary, extreme rainfall.

\section{INTRODUCTION}

According to Intergovernmental Panel on Climate Change (IPCC) reports [1,2,3], climate change is observed in all over the world: the atmosphere and oceans are warming, volume of snow and ice covers are diminishing, sea levels are rising and weather patterns are changing.

Note:

- This paper was received on April 6, 2020 and accepted for publication by the Editorial Board on November 9, 2020.

- Discussions on this paper will be accepted by May 31, 2020.

- https://doi.org/10.18400/tekderg.714980

1 Kırşehir Ahi Evran University, Civil Engineering Program, Kırşehir, Turkey sertac.oruc@ahievran.edu.tr - https://orcid.org/0000-0003-2906-0771

2 Middle East Technical University, Department of Civil Engineering, Ankara, Turkey iyucel@metu.edu.tr - https://orcid.org/0000-0001-9073-9324

3 Middle East Technical University, Institute of Marine Sciences, Ankara, Turkey ayilmaz@metu.edu.tr - https://orcid.org/0000-0001-9341-4832 
Changes resulting from global warming may include an increase in occurrence and severity of storms and other severe weather events such as extreme rainfalls [1].

There are several studies that indicate the effect of climate change on the precipitation regimes and trends. It is a common agreement that climate change will have significant effects on the water cycle and precipitation patterns [4]. In some regions, these effects are expected to change precipitation regimes (e.g. increase in the frequency and intensity of precipitation extremes [5,6]. Extreme precipitation events (e.gfewer rainy days and more extreme rainfalls) are expected by the end of the $21^{\text {st }}$ century under climate change conditions $[1,7,8,9]$. Seneviratne et al. [10] implies that in South East Asia, North East Europe, tropical Africa, and South America the impact of floods will increase, however these impacts will reverse in central Asia, Eastern Europe, central North America, and Anatolia regions.

Furthermore, there are studies that analyse future climate projections, try to figure out their consequences and reveal the potential change for the current conditions. For instance, Özturk et al. [11] examine the changes in seasonal precipitation and temperature of CORDEX Middle East and North Africa (MENA) and found out that warmer and drier conditions than present climate conditions are projected to occur more intensely. Furthermore, annual average precipitation will increase over the equatorial regions and decrease over the subtropical regions [12]. Another study that used multi-model ensemble of regional climate projections to estimate the climate change signal in terms of temperature and precipitation for the city of Aachen, Germany [13]. The results of the study reveal that rainfall is likely to decrease over the century and the examinations indicate longer and more frequent dry periods in the future. The Norwegian white paper on climate adaptation [14] indicates a rise of 5-30\% in annual mean precipitation by 2100 relative to the period 196190 and the number of days with heavy precipitation will also rise over this century.

Based on the evidence in the SREX (The Special Report on "Managing the Risks of Extreme Events and Disasters to Advance Climate Change Adaptation" of the IPCC report [15], one can say that there is significant increase in heavy precipitation events at present in more regions than there is significant decreases, but these increase and decrease show various regional and sub-regional trends [16]. Similar findings revealed by other studies; extreme weather events stated to occur more frequently and the areas that have not faced extreme events in the past started to encounter these events, both heavy rainfall increase and decrease is observed, but the areas with increasing rainfall getting larger [17, 18]. Moreover, it is found that neglecting the changing frequency may cause underestimation of extreme events [19]. Sarhadi et al. [20] show that stationary approach in frequency analyses may underestimate the magnitude (return level) of extreme precipitation events, and updated design assumption must be presented in the changing conditions.

Urban water infrastructure (e.g., sewer and stormwater management systems) and flood control structures (e.g., dams) are designed based on extreme rainfall properties and these properties are reflected as intensity-duration-frequency (IDF) curves [21,22]. The IDF curves quantify the frequency of occurrence of a storm with a specific intensity at different storm durations and it is used for many applications of urban water infrastructure design including stormwater [23]. The IDF curves are, in general, currently based on historical precipitation analysis and statistics. Infrastructure design concepts have considered stationary return levels for a long time, which assume no change to the frequency of extreme event over time however, the frequency of extremes has been changing and this change probably will 
continue in the future [19]. Moreover, it is found that neglecting the changing frequency results in IDF curves that can underestimate extreme events [19,20]. Sarhadi et al. [20] introduced a fully time varying risk framework by Bayesian Markov chain Monte Carlo techniques to incorporate the effect of nonstationarities. The results demonstrate consistent results with those of Cheng and Aghakouchak [19] and show that stationary approach may underestimate the extreme precipitation events, updated design assumption must be presented in the changing conditions and nonstationary-based IDF curves must replace the stationarybased IDF curves. Hosseinzadehtalaei et al. [22] point out the changing patterns of extreme precipitation and draw attention to the current design standards based on IDF curves that assumes no temporal change.

Climate variability affects the naturel environment from two dimensions: the long-term trend of average climate variables may be altered, or fluctuations may have a wider range which results in changes in the statistical characteristics of climate variables [1,24]. Studies support that the global hydrologic cycle will be intensified due to changing climate; wet and dry extremes will be increased which result in floods and droughts $[25,26,27]$. However, climate change projection results from GCM/RCM couplings cannot be directly used for the hydrological impact studies since they require finer temporal resolution at hourly or less particularly for extreme events [28]. Unfortunately, reliable records are available at coarse intervals such as yearly, monthly or daily and rainfall data is generally low quality. Short interval rainfall records are limited due to the high cost and insufficiency of reliable measurement and the monitoring systems [29]. In this context, disaggregation can be employed to take the advantage of using long term data which exist in low resolution or larger time scales such as daily or above [30].

Annual count of extreme events in Turkey shows an increasing trend in 1940-2019 period according to 2019 Climate Assessment Report of State Meteorological Service [31]. During 2019 most hazardous extreme events were heavy rain/floods (36\%), wind storm (27\%), hail (18\%), lightning (7\%) and heavy snow (5\%). Climate change in Turkey has been evaluated in many different studies with its different aspects. Majority of analyses that are conducted with observed and future data were focused on temperature and precipitation changes. Sensoy et al. [32] investigated the extreme climate indices in Turkey for about 109 stations and for the period from 1960 to 2010. Except Aegean and South-eastern Anatolia regions, heavy precipitation days increase in most of the stations. Furthermore, in most of the stations maximum 1-day precipitation follow an increasing trend apart from South-eastern Anatolia. In a recent study for the Rize Province in Turkey, a catchment-scale analysis of extreme rainfall events of the reference (1961-1990) and three future climate periods (2013-2039, 2040-2070, and 2071-2100) is conducted and the results projected a 30\% decrease in the median value of extreme rainfall over the study region for the near future [33]. Standard duration annual maximum rainfall series with various durations and length of 14 stations up to 2010 in Turkey are used in order to capture the statistical behavior of series and it is computed that $90 \%$ of all studied annual maximum rainfall series are trendless, independent, stationary, and homogeneous. Hence, it is concluded that Intensity-Duration-Frequency (IDF) curves can be computed in the conventional way for Turkey [34]. On the other hand statistically significant increasing trends were found in Antalya Region for at least one extreme rainfall index based on frequency analysis conducted by using Generalized Pareto Distribution (GPD) for current and future periods [35]. Rainfall intensities for different return periods increased up to $23 \%$ when compared with the current period [35]. Climate change 
and its urban-induced bias in different cities of Turkey were studied considering the temperature and precipitation data of stations for the period of 1950-2004 [36]. Particularly, significant warming is found in almost all of the regions for minimum temperature series and significant decreases of precipitation amounts are identified in the western parts of Turkey [36]. According to Turunçoğlu et al. [37], for the twenty first century all simulations of CMIP3 and CMIP5 agreed on a temperature increase and a precipitation decrease in Turkey.

Ankara, the Capital of Turkey has a semi-arid climate and significant influence by climate change that also has a continuous population growth and is located within Sakarya and Kizilirmak Basins. According to the results of the projections carried out in ClimaHydro Project [38] for these basins, there is a decrease tendency in the total precipitation compared to the reference period (1971-2000), and it is predicted that the basins will receive $8 \%$ and $6 \%$ respectively less rainfall compared to the reference period in 2071-2100 [38]. It is expected that rainfall decreases for this period will predominate in the southwestern and north-eastern parts of the Sakarya basin. Also, climate projections for Sakarya Basin, where Ankara is located, indicate that number of extreme wet days decrease for future periods, which will have a possible consequence of intensified precipitation [38]. Furthermore, in the last 20 years' flooding observations, heavy rainfall and flash flooding caused various damages to the property and even loss of life in the city. However, despite all these circumstances, the detailed studies that particularly focused on the status of intensity-duration and frequency of precipitation storms under changing climate have been lacking so far for Ankara, the Capital of Turkey.

In this study extreme precipitation properties through IDF curve analyses for Ankara are investigated by using observed (1950-2015) and future (2015-2098) precipitation data using 3 GCMs coupled with one RCM under two different carbon emission sceneries. Projected daily precipitation data is disaggregated to finer scales and Generalized Extreme Value (GEV) distribution is used to analyse observed and future data considering the stationary and nonstationary models, which assume changing frequency of extreme event over time. The projection results are directly used for the analyses due to the possible loss of nonstationary signal of the series. According to Aziz [39] and Aziz et al. [40], bias correction methods have a tendency to lose nonstationarity signals even though they improved the model performance substantially. After the bias-correction was applied he states that the impacts of nonstationarity were altered to opposite direction or lost. Maraun [41] also discussed the possibility of alteration of climate change trends and nonstationarity signals after bias correction. Moreover Willkofer [42] stated the poor performance of bias correction approaches with extreme values. Thus, in this study bias correction did not applied to the results of models in order to preserve nonstationary and trend directions."

The objectives of this study are to disaggregate daily future projections to finer scales, to investigate superiority of nonstationary GEV models to stationary GEV models for observed and future precipitation data, and to calculate return level values for observed and future period rainfall with stationary and nonstationary GEV models. 


\section{DATA AND STUDY AREA}

The annual maximum precipitation data of 5, 10, 15, 30 minutes and 1, 2, 3, 6 hours duration for 1950-2015 period for Ankara province is obtained to conduct data analysis for the observation period. This data is acquired from Turkish State Meteorological Service (SMS).

The grid based data representing Ankara province were received from Turkish State Meteorological Service (SMS) where these climate projections and their performance evaluations have already been done in detail by Demircan et al. [43]. Since our aim here in this study is to look climate change impact on IDF via nonstationarity we have not focused on performance of the models which are already available in the literature. Table 2.1 shows the location of meteorological stations and nearest projection grids to these stations as well as their altitudes. The data consists of daily projections covering 2015-2099 period however because of missing data for 2099, 2015-2098 period is used for the analyses. Also, 19712000 is chosen as model validation period. Daily projection results of three global climate models (GCM) coupled with regional climate model (RCM) (RegCM4) are used. These models are HadGEM2-ES, MPI-ESM-MR and GFDL-ESM2M and run under RCP 4.5 and RCP 8.5 emission scenarios. These model results were supplied by SMS.

Table 2.1 - Projection Data Stations \& Grids

\begin{tabular}{|c|c|c|c|c|c|c|c|c|}
\hline \multirow[b]{2}{*}{ No } & \multirow[b]{2}{*}{ Station } & \multirow[b]{2}{*}{ Grid } & \multicolumn{3}{|c|}{ Station } & \multicolumn{3}{|c|}{ Grid } \\
\hline & & & Latitude & Longitude & $\begin{array}{c}\text { Altitude } \\
\text { mt }\end{array}$ & Latitude & Longitude & $\begin{array}{c}\text { Altitude } \\
\text { mt }\end{array}$ \\
\hline 17129 & $\begin{array}{l}\text { ETİMESGUT } \\
\text { HAVALİMANI }\end{array}$ & 2733 & 39,9558 & 32,6854 & 806 & 39,9661 & 32,6608 & 1028 \\
\hline 17131 & $\begin{array}{l}\text { ANKARA } \\
\text { GÜVERCINLIK } \\
\text { HAVALIMANI }\end{array}$ & 2733 & 39,9343 & 32,7387 & 820 & 39,9661 & 32,6608 & 1028 \\
\hline
\end{tabular}

Rainfall/frequency analysis is conducted for daily projections of three model and two scenarios of grid no 2733 for the projection (2015-2098) period. However, daily temporal resolution from projection data is not well suited for the extreme value analysis. For instance, urban flash flooding is caused by heavy rainfalls over short durations such as in a few minutes to hours therefore it is essential to analyse extreme rainfalls for shorter durations such as subdaily or sub-hourly. For this reason, daily RCM output data is disaggregated to finer time scales such as hourly and sub-hourly to use future projections for extreme value analysis [44]. For the disaggregation process, temporal stochastic simulation of rainfall process at high resolution, based on the Bartlett-Lewis rectangular pulse model is used $[45,46]$.

Stationary and nonstationary rainfall return levels (in $\mathrm{mm}$ ) for return periods $2,5,10,25,50$, 100, 200 years are derived for observed (1950-2015) and projected data (2015-2098) for extreme rainfall time series of the sub-hourly and hourly annual maximum data.

Ankara is located in the northwest of Central Anatolia. The city is like a pot surrounded by four mountains of Anatolia Plateau with an altitude of 850-1000 meters. These mountains are: Karyağdı on the north, İdris on the east, Elmadağ on the south and southeast and Çal on the southwest (Figure 2.1). 


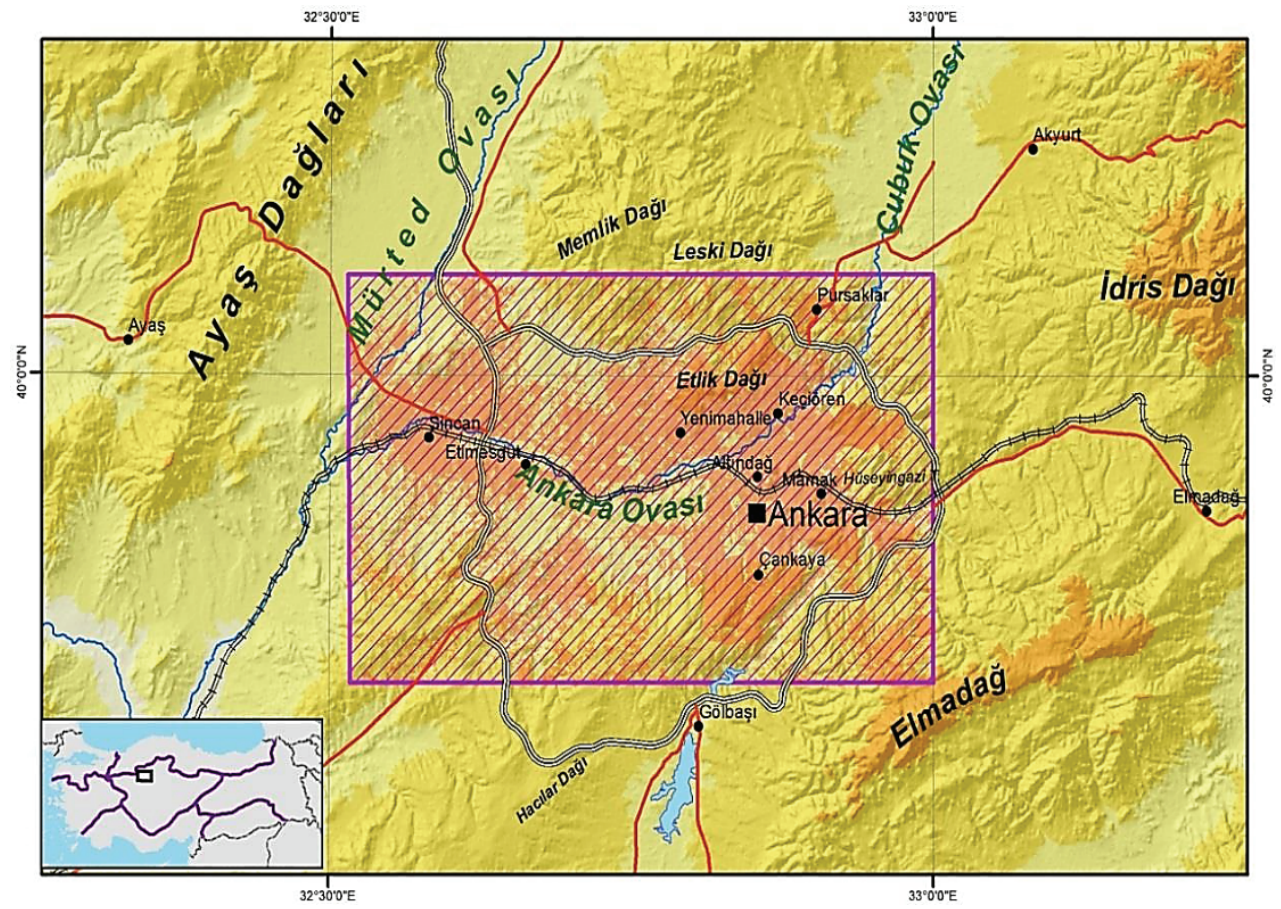

Figure 2.1 - Location of Ankara [47]

Between these mountains three rivers flow. Çubuk creek between Karyağdı and İdris mountains, Bent Stream between Elmadağ and İdris Mountains and finally İncesu creek between Elmadağ and Çal mountains; these rivers come together between Karyağdı and Çal mountains and flow into Sakarya River as Ankara stream. A population of 5.3 million people (TÜIK, 2016) are living in the capital Ankara and 88\% of the population lives in the city center [48]. Ankara is generally known for its twentieth century development as the designed capital of the newly born Turkish nation-state and the city's growth at the beginning displayed a typical example of modernization efforts. The second half of the century compared to the first years, witnessed the uncontrollable expansion and transformation of the city with expanding squatter areas due to heavy migration [49].

According to Thornthwaite classification, the climate in Ankara is a second degree mesothermal semi-arid and less-humid climate with intensive water surplus in winter months. The mean temperature of Ankara and its surroundings is above $20.0^{\circ} \mathrm{C}$ in three months (June, July and August), it is between $10.0-20.0^{\circ} \mathrm{C}$ in four months (April, May, September and October) and it is below $10.0^{\circ} \mathrm{C}$ in five months of the year (November, December, January, February and March). The values of some meteorological parameters for Ankara are as follow: the annual mean temperature is $11.9{ }^{\circ} \mathrm{C}$, the mean temperature in January is $0.2{ }^{\circ} \mathrm{C}$, the mean temperature in July is $23.5^{\circ} \mathrm{C}$, the mean annual precipitation is $387 \mathrm{~mm}$, and the mean annual relative humidity is around 60. In Ankara and its surroundings, in the cold period, there are heavily cyclonic activities. As a result of this, frontal precipitation is effective in the cold period. However, in the warm period, anticyclonic conditions are 
dominant. Because of this, convective precipitation occurs in the warm period, also there are big differences between day and night temperature and winter and summer temperature because of continental climate conditions [50,51].

\section{METHODOLOGY}

The methodology of precipitation analysis in this study consists of;

(1) Projected data is disaggregated into finest scale (5 minutes) and then it is aggregated to next analysis time scales (such as 10,15, and 30 minutes) because each run generates rainfall depths that are independent from the other runs and subsequently the data at higher time scales may be inconsistent.

(2) Trend analysis is carried out for observed and projected data.

(3) Stationary GEV (St) models are developed; return levels are derived for desired return periods for observed and projected data.

(4) Non-stationary GEV (NSt) models are developed; return levels are derived for desired return periods for observed and projected data.

A general framework for rainfall analyses used in this study can be seen in Figure 3.1.

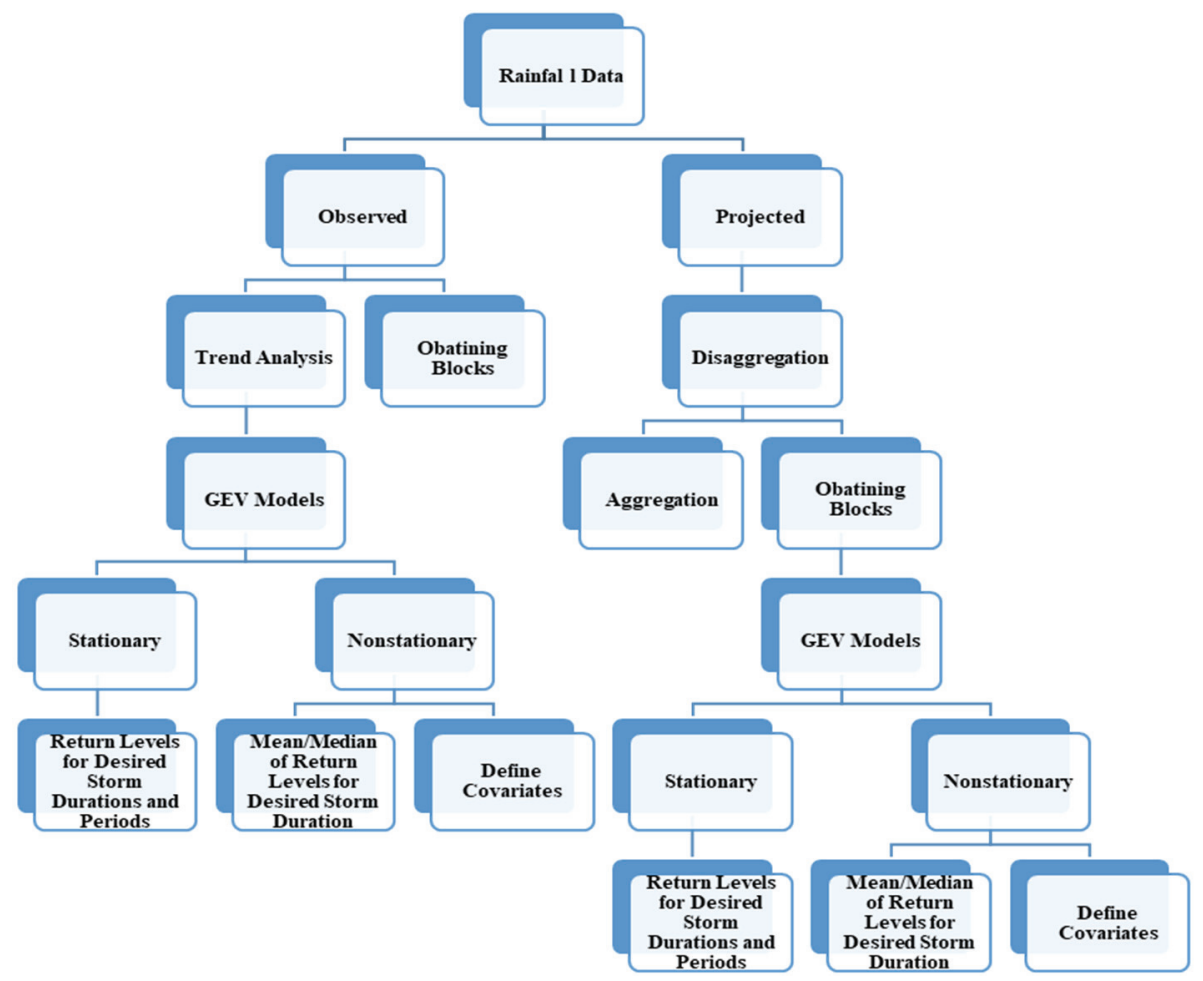

Figure 3.1 - Rainfall Data Analyses Framework 


\subsection{Disaggregation}

Daily projected precipitation data is first disaggregated to 5 minutes duration and then for the use of GEV analyses the 5-min data is aggregated to 10, 15 minutes and 1, 6 hours storm duration. A complete software package for the temporal stochastic simulation of rainfall process at fine time scales which is developed in the $\mathrm{R}$ programming environment, HyetosMinute, is used to prepare daily data for extreme value analysis and used for the disaggregation process in this study. Disaggregation is based on the Bartlett-Lewis rectangular pulse model which provides temporal stochastic simulation of rainfall process at fine time scales [30, 44, 45, 46, 52].

The Bartlett-Lewis Rectangular Pulses (BLRP) model is used in many studies to disaggregate daily observed rainfall to finer scales. A member of general category of Poissoncluster models in which rectangular pulses occur in continuous time simulates rainfall events with clusters of these rectangular pulses $[28,46,53,54,55]$.

The initially proposed model has 5 parameters $[55,56]$ but Random Parameter Bartlett-Lewis Rectangular Pulse Model (BLRPR) which have 6 parameters: $\{\lambda, \alpha, v, \kappa, \varphi, \mu X\}$, and is modified version of original model to enhance the model's flexibility in generating a greater diversity of rainfalls, is the preferred model in this study [44, 45, 53].

To calculate model parameters in disaggregation method, an enhanced version of the evolutionary annealing-simplex optimization method is used [30,57,58]. Mean, variance, covariance and probability of dry days are used as historical statistics for the objective function of the desired time scale (in this case five minutes). It is stated that the distribution of the maximum rainfall depths/heights can be better derived if the inter-annual variability of monthly statistics is incorporated in the parameter estimation process of the model. Therefore, in this study only the historical daily parameters are used for the optimization process and to make an adequate estimation every month is calculated separately and then combined by year. In the end, a set of parameters (in this case six parameters) are obtained for implementation in disaggregation.

\subsection{Trend analysis}

The statistical tools that provide trend tests are generally divided into two fundamental groups: Parametric and non-parametric. The non-parametric tests are said to be more appropriate to conduct trend analysis for the non-normally distributed hydro-meteorological time series data [59]. Mann-Kendall (MK) trend test is one of the non-parametric tests for trend detection and is used to detect if there is a monotonic upward or downward trend over time for precipitation in this study $[60,61,62]$. MK test is a rank-based test which has been commonly applied to hydrometeorological time series data to detect trends $[19,59,63,64]$.

\subsection{Extreme value analysis: stationary \& nonstationary}

Extreme value theory (EVT) is concerned with the statistical properties of the tails of distributions and provides the necessary methods to estimate the distribution of the extremes of a time series [65]. By this way quantification of the return values and return periods of extreme events become possible. EVT uses probabilistic distribution functions such as 
Generalized Extreme Value (GEV) or Generalized Logistic (GL) function to annual maximum (AM) series or Generalized Pareto Distribution (GPD) function which is fitted on peak-over-threshold (POT) series [66]. GEV distribution function is used in the present study to fit the observed and future precipitation data. The methodology is widely used in engineering applications that need an assessment of extreme environmental conditions [67].

The GEV distribution function has theoretical justification for fitting to block maxima (maxima of long blocks of data, e.g., annual maximum values of daily precipitation height) of data $[65,68,69]$. The GEV distribution function (df) is given by $(2.1)$.

$G(z)=\exp \left[-\left\{1+\xi\left(\frac{\mathrm{z}-\mu}{\sigma}\right)\right\}_{+}^{-\frac{1}{\xi}}\right]$

$\sigma>0,-\infty<\mu, \xi<\infty[70]$.

The GEV distribution has three parameters including location $(\mu)$, scale $(\sigma)$ and shape $(\xi)$ parameters.

Equation 2.1 covers three types of df's depending on the sign of the shape parameter, $\xi$. The Fréchet df results from $\xi>0$, and the Weibull df when $\xi<0$. The Gumbel type is obtained by taking the limit as $\xi \rightarrow 0$ [71].

Yilmaz and Perera [59] indicate that Maximum Likelihood Estimation (MLE) method is a preferred method for parameter estimation of nonstationary models due to its suitability for incorporating nonstationarity into the distribution parameters as covariates. In order to obtain nonstationary models, distribution parameters are set to be a function of covariates such as time, temperature, etc. and for every value of covariate, a unique return level value is calculated. Non-stationarity can occur either as a gradual trend or a sudden shift [72]. Time (and other covariates) variant/dependent parameters are used to capture the non-stationarity of the time series $[73,74]$. First for the stationary cases than for the non-stationary cases, extreme value analysis is applied by using GEV models. For non-stationary case, the location parameter and/or scale parameter are set to be a function of time or other variants such as annual precipitation or temperature. Different combinations for nonstationary cases are tested and compared to find out the best fitted model among stationary and nonstationary models. In the present study, all model parameters set constant for the stationary case, and location and/or scale parameters assumed to be a function of time and/or temperature for the nonstationary case. The non-stationary models that describe each of these cases with their developed parameters are explained in Table 3.1. Several variables such as temperature, time are incorporated into non-stationary models as covariates to capture the changes in extreme precipitation characteristics. (Table 3.1.). While there are other covariates such as NAO, AO, etc., time and annual average temperature were chosen because of the widespread application of time and data availability. The covariates were restricted with these ones since amount of calculations and results increase for each time series with 3 model and 2 RCPs.

Performance of fitted models is inspected by goodness-of-fit indicators such as, Akaike Information Criterion (AIC), Bayesian Information Criterion (BIC) and Negative LogLikelihood (NLL) $[65,75,76,77,78]$. 
Table 3.1 - Non-stationary models with time and covariate (average annual temperature) dependent location and scale parameters. The number 1 through 8 represents respectively storm duration for $5 \mathrm{~min}, 10 \mathrm{~min}, 15 \mathrm{~min}, 30 \mathrm{~min}, 1 \mathrm{hr}, 2 \mathrm{hr}, 3 \mathrm{hr}$, and $6 \mathrm{hr}$.

\begin{tabular}{llll}
\hline \multicolumn{1}{c}{ Model } & \multicolumn{1}{c}{ Location } & \multicolumn{1}{c}{ Scale } & \multicolumn{1}{c}{ Shape } \\
\hline NStGEV1 & $\mu \mathrm{t}=\beta_{0}+\beta_{1} \mathrm{t}$ & $\sigma$ (constant) & $\xi$ (constant) \\
NStGEV2 & $\mu \mathrm{t}=\beta_{0}+\beta_{1} \mathrm{t}$ & $\sigma \mathrm{t}=\beta_{0}+\beta_{1}$ & $\xi$ (constant) \\
NStGEV3 & $\mu$ (constant) & $\sigma \mathrm{t}=\beta_{0}+\beta 1_{\mathrm{t}}$ & $\xi$ (constant) \\
NStGEV4 & $\mu \mathrm{t}=\beta_{0}+\beta_{1}$ temperature & $\sigma$ (constant) & $\xi$ (constant) \\
NStGEV5 & $\mu \mathrm{t}=\beta_{0}+\beta_{1} \mathrm{t}$ & $\sigma \mathrm{t}=\beta_{0}+\beta_{1} \exp ($ temperature) & $\xi$ (constant) \\
NStGEV6 & $\mu \mathrm{t}=\beta_{0}+\beta_{1} \exp ($ temperature $)$ & $\sigma \mathrm{t}=\beta_{0}+\beta_{1} \exp ($ temperature) & $\xi$ (constant) \\
NStGEV7 & $\mu \mathrm{t}=\beta_{0}+\beta_{1} \exp ($ temperature) & $\sigma \mathrm{t}=($ constant) & $\xi$ (constant) \\
NStGEV8 & $\mu$ (constant) & $\sigma \mathrm{t}=\beta_{0}+\beta_{1}$ temperature & $\xi$ (constant) \\
\hline
\end{tabular}

\section{RESULTS AND DISCUSSION}

\subsection{Climate Change and Alterations in the Precipitation Regime: Observations}

\subsubsection{Trend Analysis}

Stationary and nonstationary models are applied to a 5-10-15-30 minutes and 1-2-3-6 hours observed (1950-2015) annual maximum storm durations for Ankara province. If a statistically significant trend in time series is detected, then it is accepted that the assumption of stationarity is violated. However, time series that did not present significant trend may also reveal superior results by nonstationary models. Visual inspection is an alternative to make rough inferences but for reliable determination, especially with complex variations and long-term series, statistical tests are needed. Figure 4.1 and Figure 4.2 demonstrate the trend for observed sub-hourly (5-10-15-30 minutes) and hourly (1-2-3-6 hours) time series of annual maximum rainfall intensities with a linear trend line between 1950-2015 period. A simple linear trend line visually indicates the downward (decreasing) trend for most of the time series.

MKtrend test is applied to time series for all storm durations and results are shown in Table 4.1. Bold ones indicate significant trend for $0.05(* *)$ and $0.10(*)$ significant levels. Trends particularly in sub-hourly durations and long storm durations are largely different in terms of statistical significance but not in direction. According to MK statistics; the null hypothesis that there is no trend is rejected for the 5-10-15-30 minutes and 1 hour time series. The results suggest that there is significantly a downward monotonic trend based on 5 and 10 percent significance between 1950-2015 period. 


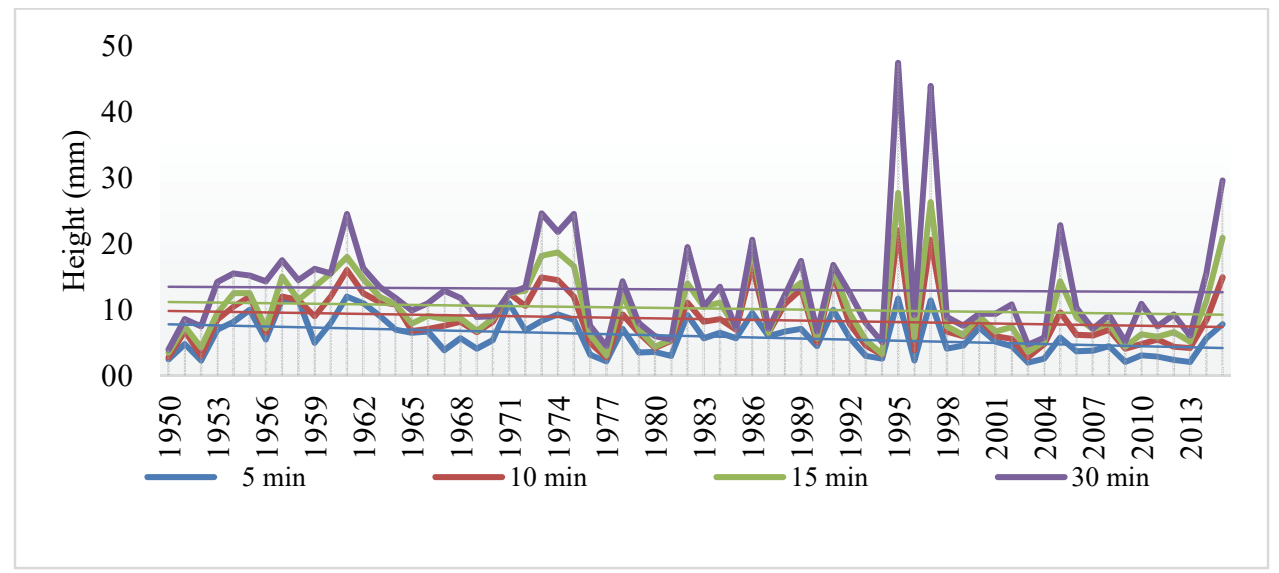

Figure 4.1 - Observed Sub-Hourly Time Series Trend

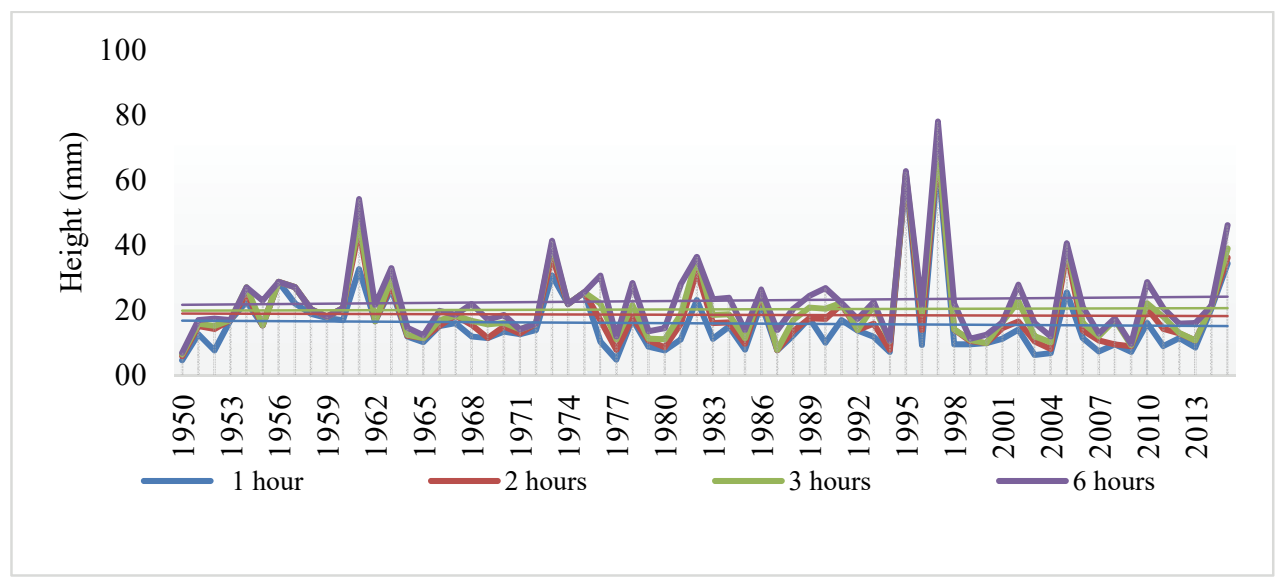

Figure 4.2 - Observed Hourly Time Series Trend

Table 4.1 - Mann-Kendall Results for the Storm Durations

\begin{tabular}{lll}
\hline \multicolumn{1}{c}{ Storm Duration } & \multicolumn{1}{c}{ MK Statistic } & \multicolumn{1}{c}{ p-Value } \\
\hline 5 Minutes & tau $=\mathbf{- 0 . 2 6 0}$ & $\mathbf{0 . 0 0 2 1 6 1 6 * *}$ \\
\hline 10 Minutes & tau $=\mathbf{- 0 . 1 8 7}$ & $\mathbf{0 . 0 2 7 9 5 1 * *}$ \\
\hline 15 Minutes & tau $=\mathbf{- 0 . 1 4 3}$ & $\mathbf{0 . 0 9 1 3 7 2 *}$ \\
\hline 30 Minutes & tau $=\mathbf{- 0 . 1 4 8}$ & $\mathbf{0 . 0 8 0 2 6 2 *}$ \\
\hline 1 Hour & tau $=\mathbf{- 0 . 1 8 9}$ & $\mathbf{0 . 0 2 5 6 9 9 * *}$ \\
\hline 2 Hour & tau $=-0.136$ & 0.10726 \\
\hline 3 Hour & tau $=-0.0565$ & 0.50656 \\
\hline 6 Hour & tau $=-0.0266$ & 0.75662 \\
\hline
\end{tabular}

** $-0,05$ significance level, $*_{-} 0,1$ significance level 


\subsubsection{Stationarity vs Nonstationarity Analysis}

Maximum precipitation and recurrence analysis rely on observation for at least 10 years of station precipitation data. SMS determines the annual maximum precipitation depths for storm durations of 5, 10, 15, $30 \mathrm{~min}$, and 1, 2, 3, 4, 5, 6, 8, 12, 18, 24 hours. IDF analysis is performed for the 2, 5, 10,25,50 and 100-year repetition periods using the probability density functions namely; Log-Normal 2 Distribution (LN2), Log-Normal 3 Distribution (LN3), 2parameter Gamma Distribution (G2P), Log-Pearson 3 Distribution (LP3), and Gumbel Distribution (G). The best fit among these functions is found by the Chi Square and Kolmogorov-Smirnov conformity tests. As a result, a stationary LP3 is selected as the preferred distribution for the selected station and it is based on the data from 1940-2015 period. In this study, SMS annual maximum precipitation statistics are used as reference to compare them with results obtained GEV based stationary and nonstationary analyses. This can enable us to see variations between the data officially in use and data acquired within this current study.

Table 4.2. presents the negative log-likelihood (NLL), AIC and BIC diagnostic values of stationary and best fit nonstationary models. Small negative log-likelihood and AIC/BIC values infer the superiority of the model to the other ones. Consistently, for all storm durations the proper nonstationary models provided the lower performance scores than stationary models. This implies the worthy of consideration of changing climate conditions in precipitation frequency analysis.

Table 4.2 - Stationary and Best Fit Nonstationary Model Comparison

\begin{tabular}{lccclccc}
\hline \multicolumn{1}{c}{ Model } & N L L & AIC & BIC & \multicolumn{1}{c}{ Model } & N L L & AIC & BIC \\
\hline StFiveMin & 160 & 327 & 333 & StTenMin & 182 & 369 & 376 \\
NStFiveMin & 139 & 288 & 298 & NStTenMin & 166 & 342 & 353 \\
StFifteenMin & 194 & 394 & 401 & StThirtyMin & 210 & 426 & 432 \\
NStFifteenMin & 173 & 356 & 367 & NStThirtyMin & 190 & 390 & 401 \\
& & & & & & & \\
StOneHour & 222 & 451 & 457 & StTwoHours & 228 & 461 & 468 \\
NStOneHour & 201 & 412 & 423 & NStTwoHours & 205 & 420 & 431 \\
& & & & & & & \\
StThreeHours & 231 & 468 & 474 & StSixHours & 237 & 480 & 487 \\
NStThreeHours & 209 & 428 & 439 & NStSixHours & 216 & 442 & 452
\end{tabular}

The changes between return levels of best fit nonstationary model and stationary ones for each return period are shown in Table 4.3. Generally mean or median values are computed to simplify the results of nonstationary models because nonstationary return levels take different values for every single point of covariate. 
Table 4.3 - Nonstationary GEV Best Fit Model Return Levels (mm) - Mean and Median Value Change with Respect to Stationary GEV Model Return Level Results - Observation Period

\begin{tabular}{|c|c|c|c|c|c|c|c|}
\hline & 2 year & 5 year & 10 year & 25 year & 50 year & 100 year & 200 year \\
\hline \multicolumn{8}{|c|}{ Mean Value Change } \\
\hline FiveMin & $-4 \%$ & $-4 \%$ & $-5 \%$ & $-9 \%$ & $-11 \%$ & $-15 \%$ & $-18 \%$ \\
\hline TenMin & $-14 \%$ & $-13 \%$ & $-12 \%$ & $-9 \%$ & $-7 \%$ & $-5 \%$ & $-3 \%$ \\
\hline FifteenMin & $-1 \%$ & $-4 \%$ & $-6 \%$ & $-9 \%$ & $-12 \%$ & $-14 \%$ & $-17 \%$ \\
\hline ThirtyMin & $0 \%$ & $-3 \%$ & $-6 \%$ & $-10 \%$ & $-13 \%$ & $-16 \%$ & $-19 \%$ \\
\hline OneHour & $-7 \%$ & $-5 \%$ & $-3 \%$ & $0 \%$ & $3 \%$ & $6 \%$ & $10 \%$ \\
\hline TwoHours & $0 \%$ & $-3 \%$ & $-4 \%$ & $-5 \%$ & $-6 \%$ & $-7 \%$ & $-7 \%$ \\
\hline ThreeHours & $0 \%$ & $-3 \%$ & $-5 \%$ & $-8 \%$ & $-11 \%$ & $-13 \%$ & $-16 \%$ \\
\hline SixHours & $1 \%$ & $-1 \%$ & $-2 \%$ & $-3 \%$ & $-4 \%$ & $-5 \%$ & $-5 \%$ \\
\hline \multicolumn{8}{|c|}{ Median Value Change } \\
\hline FiveMin & $-3 \%$ & $-2 \%$ & $-4 \%$ & $-7 \%$ & $-9 \%$ & $-12 \%$ & $-15 \%$ \\
\hline TenMin & $-13 \%$ & $-12 \%$ & $-10 \%$ & $-7 \%$ & $-4 \%$ & $-2 \%$ & $0 \%$ \\
\hline FifteenMin & $-1 \%$ & $-2 \%$ & $-4 \%$ & $-7 \%$ & $-9 \%$ & $-12 \%$ & $-14 \%$ \\
\hline ThirtyMin & $1 \%$ & $-2 \%$ & $-5 \%$ & $-8 \%$ & $-10 \%$ & $-13 \%$ & $-16 \%$ \\
\hline OneHour & $-8 \%$ & $-5 \%$ & $-2 \%$ & $2 \%$ & $5 \%$ & $8 \%$ & $12 \%$ \\
\hline TwoHours & $-1 \%$ & $-2 \%$ & $-3 \%$ & $-4 \%$ & $-4 \%$ & $-5 \%$ & $-5 \%$ \\
\hline ThreeHours & $-1 \%$ & $-2 \%$ & $-4 \%$ & $-7 \%$ & $-9 \%$ & $-11 \%$ & $-14 \%$ \\
\hline SixHours & $0 \%$ & $-1 \%$ & $-2 \%$ & $-2 \%$ & $-3 \%$ & $-3 \%$ & $-4 \%$ \\
\hline
\end{tabular}

In addition, Figure 4.3 shows return levels of stationary model, nonstationary mean and median and SMS for each storm duration from $5 \mathrm{~min}$ to $6 \mathrm{hr}$, respectively. By examining storm durations, it is found that the shorter the duration the larger the differences between the non-stationary and stationary extremes. In the design of storm drainage systems short durations of maximum rainfall events are mostly considered. Therefore, the use of nonstationary approach in determining the design value should be more preferable depending on safety and economical scale. For an example, for the 100 -year return period, the differences between stationary and nonstationary mean (median) return level of 5 minutes and 30 minutes events are $15 \%(12 \%)$ and $16 \%(13 \%)$, while for a 6 hours storm, the difference is $5 \%(3 \%)$. Also, among the storm durations, only one hour time series exhibit larger values (increase) for its nonstationary model return level values, however this is not the case for shorter return periods from 2 years to 10 years. 
Investigation of the Effect of Climate Change on Extreme Precipitation: ...
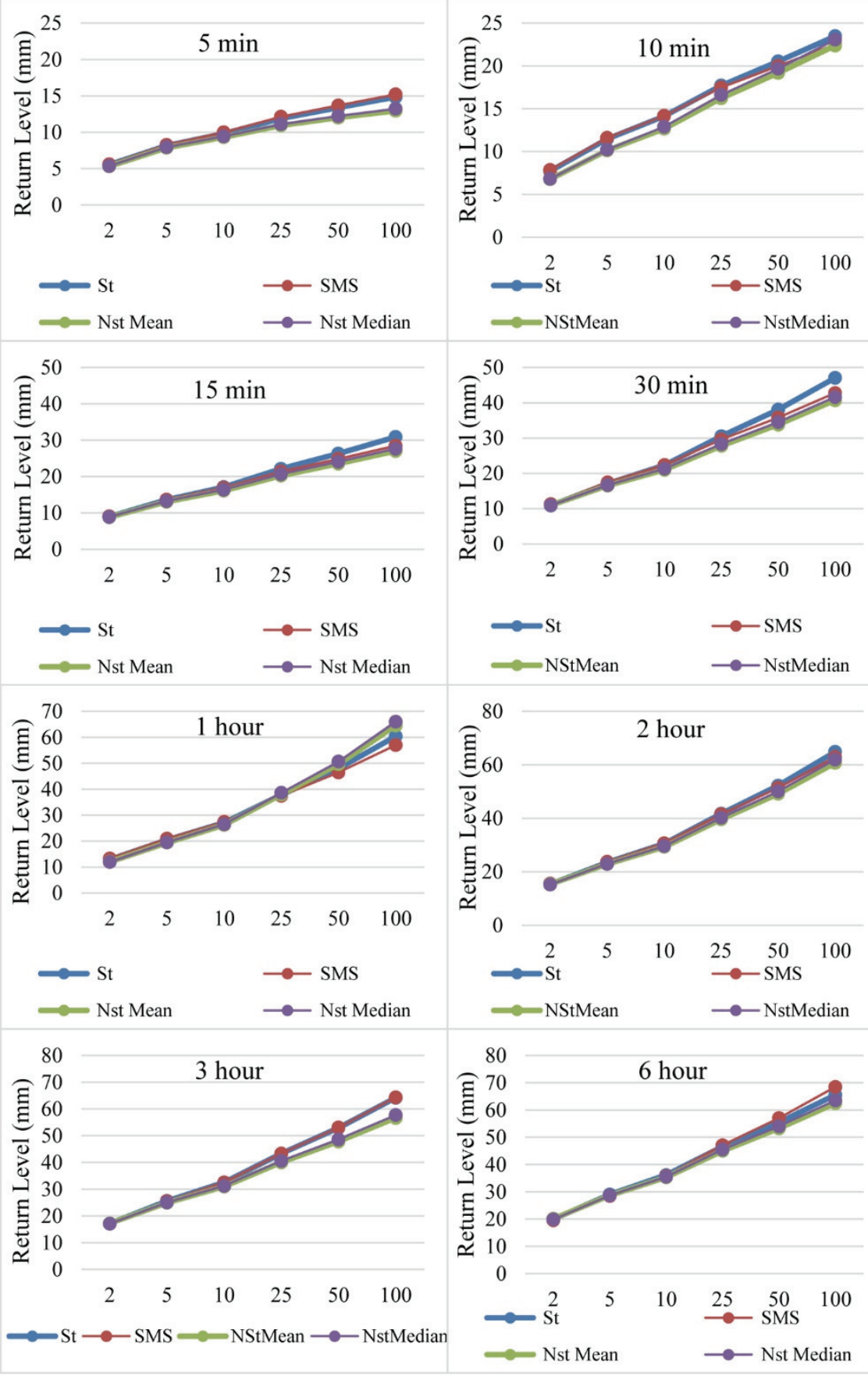

Figure 4.3 - Stationary and best fit nonstationary model return level ( $\mathrm{mm}$ ) comparison Return level (mm) vs. Return period (Year) 
Differences in sub-hourly return levels between nonstationary and stationary models increase with the increasing return period, except the results from ten minutes data. While the mean (median) difference of 5-year return period is $4 \%(2 \%)$ for five and fifteen minutes durations, this difference reaches $11 \%(9 \%)$ and $12 \%(9 \%)$ for 50 years return period and $15 \%(12 \%)$ and $14 \%(12 \%)$ for 100 years return period. Exceptionally, ten minutes data follows the opposite direction for the alteration of nonstationary and stationary return level results with respect to storm duration, such as $14 \%(13 \%)$ and $12 \%(10 \%)$ mean (median) difference for 2 and 10 years return period and 5\% (2\%) for 100 years return period. It should be noted that usually the low return periods ( 2 to 10 years) are considered in design steps of storm drainage systems and this makes the nonstationarity more critical in controlling the uncertainty related to the determination of maximum precipitation value. The hourly time series demonstrate similar behavior to sub-hourly time series. While the negative differences from two, threeand six-hours time series are amplified with increasing return period, one-hour time series show increased return levels (positive difference) with nonstationarity after 25 years return period. SMS based stationary return levels also follow GEV based stationary levels closely and both of them provides higher return levels than nonstationary models (see Figure 4.3). The difference between the stationary and nonstationary return levels is not following a linear trend but to make a general inference sub-hourly storm durations indicate larger difference than hourly storm durations and non-stationary estimates are smaller than their corresponding stationary values. In these circumstances for a worst-case scenario it is better to use stationary return level estimates for the safety issue of a hydraulic structure. However, it will increase the cost and result in overdesign when observed data is considered. Moreover, depending on the characteristics of a time series different results can be seen; even one value can change the calculation results since every time series are evaluated independently and have its own statistical attributes. The outlier effect, distribution, parameter estimation methods, etc., all have impacts over the return level results. For instance, while observed 3 hour rainfall exceed 1 hour rainfall height, according to statistical analyses, chosen distribution, etc. a 100 year-1 hour return level result can exceed the 100 year-3 hour result; at that case distribution may change and calculations can be repeated, parameter estimation method can be changed or the highest value is taken for the calculations. Therefore, analyses and interpretation of such results need expert judgement to avoid misinterpretation.

\subsection{Climate Change and Alterations in the Maximum Precipitation Events: Projections}

Daily precipitation values of projection period are disaggregated to 5 minutes storm durations, then five minutes time series aggregated to the storm durations that are subject of interest such as $10 \mathrm{~min}, 15 \mathrm{~min}, 1$ hour and 6 hour. Stationary and nonstationary models are applied to these projected (2015-2098) annual maximum storm durations for Ankara province. Three GCM models (MPI-ESM-MR, HADGEM2-ES, and GFDL-ESM2M) and two RCP scenario (4.5 and 8.5) for storm durations of stationary and nonstationary models are used. These driving GCM model outputs are downscaled by using the RegCM4 regional model to produce daily precipitation at $10 \mathrm{~km}$. 


\subsubsection{Disaggregation of Daily Precipitation}

The performance of the aforementioned disaggregation method has been assessed by reproducing a set of standard statistics (mean, variance, proportion of dry day, skewness, standard error and maximum value) for one hour disaggregated precipitation intensity from 24 hours precipitation data. These statistics can be compared with the same statistics obtained from hourly observed precipitation data available at the model grid location. The hourly mean statistics for January, May, June and October representing winter, spring, summer, and fall seasons, respectively are calculated for hourly and disaggregated hourly observed data and they are shown in Table 4.4. The statistics results are close to each other particularly in spring, summer and fall seasons. The higher skewness and maximum precipitation depth are observed with disaggregated data in January. However, the results indicated a good performance of the methodology in producing hourly values with their mean statistical measures (Table 4.4.). On the other hand, it must be specified the larger bias of the disaggregated data with respect to observed data for finer durations such as five minutes or ten minutes are observed. The parameters developed with observed data are used in the model to disaggregate daily precipitation of climate model outputs.

Table 4.4 - Statistical Parameters of Observed and Disaggregated Hourly Precipitation

\begin{tabular}{lcccccccc}
\hline & $\begin{array}{l}\text { January } \\
\text { Disagg. }\end{array}$ & $\begin{array}{l}\text { January } \\
\text { Obs }\end{array}$ & $\begin{array}{l}\text { May } \\
\text { Disagg. }\end{array}$ & $\begin{array}{l}\text { May } \\
\text { Obs }\end{array}$ & $\begin{array}{l}\text { June } \\
\text { Disagg. }\end{array}$ & $\begin{array}{l}\text { June } \\
\text { Obs }\end{array}$ & $\begin{array}{l}\text { October } \\
\text { Disagg. }\end{array}$ & $\begin{array}{l}\text { October } \\
\text { Obs }\end{array}$ \\
\hline Mean & 0,04 & 0,04 & 0,11 & 0,11 & 0,09 & 0,09 & 0,07 & 0,07 \\
\hline Variance & 0,30 & 0,11 & 0,37 & 0,37 & 0,26 & 0,29 & 0,23 & 0,16 \\
\hline Dry Day & 0,98 & 0,95 & 0,90 & 0,90 & 0,91 & 0,93 & 0,95 & 0,93 \\
\hline Skewness & 15,52 & 11,24 & 9,25 & 9,54 & 9,99 & 8,69 & 10,25 & 11,40 \\
\hline Std Error & 0,55 & 0,34 & 0,61 & 0,61 & 0,51 & 0,54 & 0,47 & 0,40 \\
\hline Maximum & 10,34 & 5,80 & 8,90 & 9,80 & 7,85 & 7,40 & 7,52 & 7,60 \\
\hline
\end{tabular}

\subsubsection{Trend Analysis}

Figure 4.4 shows projected annual maximum rainfall intensities for storm duration of 10, 15 minutes and 1, 6 hours for three models and two RCP scenarios, between 2015-2098 periods with a linear trend line. All projections for $10 \mathrm{~min}, 15 \mathrm{~min}$ and 1-hr generally show decreasing tendency for their annual maximum precipitation depths according to linear regression lines. For sub-hourly durations, GFDL 8.5 and HG 8.5 are almost unresponsive to interannual changes in maximum precipitation. HG4.5, MPI4.5, and MPI8.5 are the most sensitive models to maximum precipitation changes between years for 15 min duration. Also, MPI8.5 shows higher fluctuations between years for 1-hr duration. As duration changes different responses from each model are observed.

Trend test results using MK are shown in Table 4.5. The null hypothesis that there is no trend is rejected is shown with bold. The directions of trends in projections regardless of storm durations are mostly downward. The significant decreasing trends are associated with GFDL and MPI models with 8.5 RCP scenario while RCP 8.5 produces the warmest environment. 


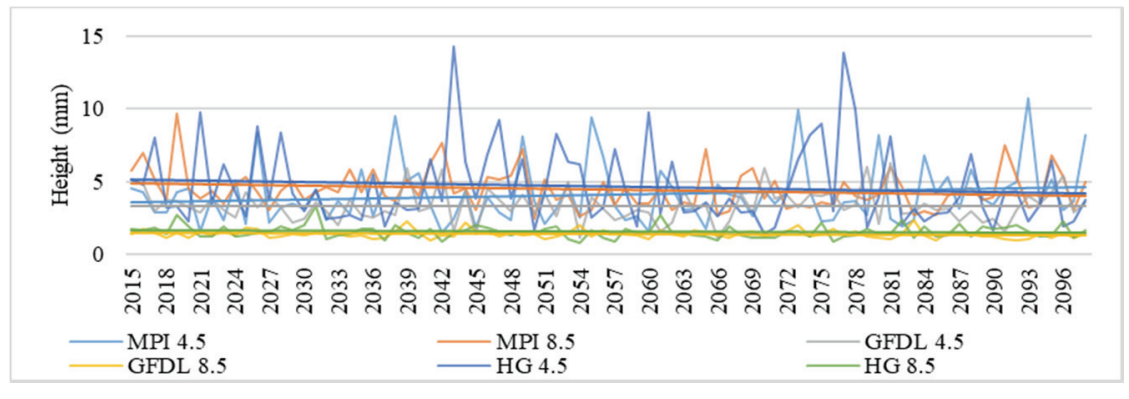

a
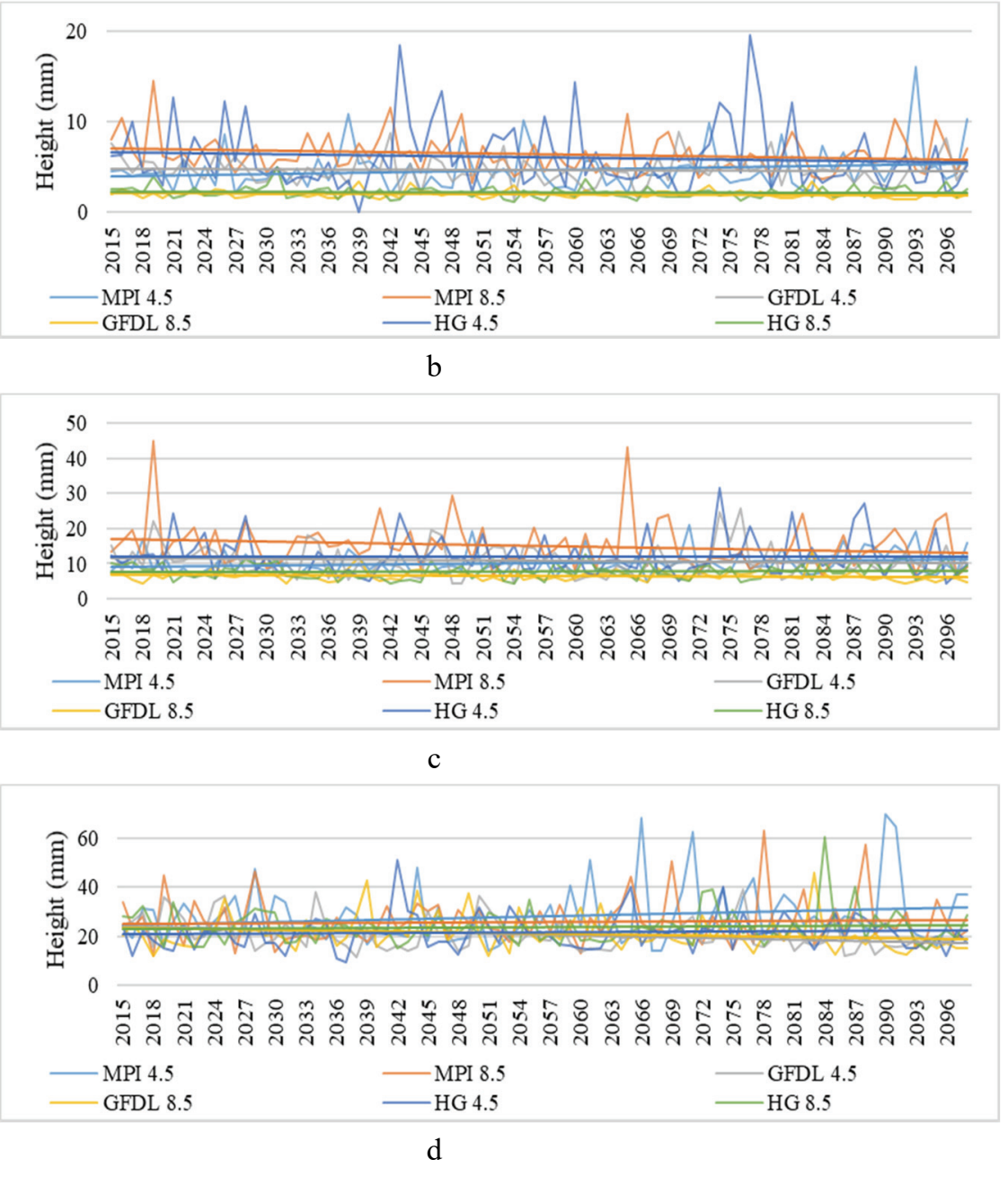

Figure 4.4 - Projected Annual Maximum-Time Series in Ankara Province for 2015-2098 period: a) Ten Minutes, b) Fifteen Minutes, c) One Hour, d) Six Hours 
Moreover, increasing trends occurred only with MPI4.5 for each of storm duration. The MPI model can be sensitive to the choice of RCP scenario as it produces trend at opposite directions with different RCP. Trends in short (in particular sub-hourly) and long storm durations are largely different in terms of statistical significance and directions for model and scenario combinations.

Table 4.5 - Mann-Kendall Results for the Storm Durations of Projected Data Time Series

\begin{tabular}{llllll}
\hline & MK & $\mathbf{p}-$ & & \multicolumn{2}{l}{ MK } \\
Storm Duration & Statistic & Value & Storm Duration & Statistic & Value \\
\hline TenMinutesMPI45 & 0.0947 & 0.20374 & OneHourMPI45 & 0.112 & 0.1339 \\
\hline TenMinutesMPI85 & $\mathbf{- 0 . 1 4}$ & $\mathbf{0 . 0 5 9 4 0}$ & OneHourMPI85 & $\mathbf{- 0 . 1 4 3}$ & $\mathbf{0 . 0 5 5 3 5}$ \\
\hline TenMinutesGFDL45 & -0.0175 & 0.8167 & OneHourGFDL45 & -0.0694 & 0.35185 \\
\hline TenMinutesGFDL85 & -0.105 & 0.15966 & OneHourGFDL85 & $\mathbf{- 0 . 1 4 1}$ & $\mathbf{0 . 0 5 8 8 8}$ \\
\hline TenMinutesHG45 & -0.0967 & 0.19428 & OneHourHG45 & -0.0402 & 0.59128 \\
\hline TenMinutesHG85 & -0.0531 & 0.47717 & OneHourHG85 & 0.0499 & 0.50392 \\
\hline FifteenMinutesMPI45 & 0.0895 & 0.22959 & SixHoursMPI45 & 0.0602 & 0.41944 \\
\hline FifteenMinutesMPI85 & $\mathbf{- 0 . 1 1 8}$ & $\mathbf{0 . 1 1 2 3 5}$ & SixHoursMPI85 & -0.0115 & 0.88024 \\
\hline FifteenMinutesGFDL45 & -0.0459 & 0.53906 & SixHoursGFDL45 & $\mathbf{- 0 . 1 7 3}$ & $\mathbf{0 . 0 1 9 8 3}$ \\
\hline FifteenMinutesGFDL85 & $\mathbf{- 0 . 1 2 2}$ & $\mathbf{0 . 1 0 1 4 2}$ & SixHoursGFDL85 & $\mathbf{- 0 . 1 9 9}$ & $\mathbf{0 . 0 0 7 5 9}$ \\
\hline FifteenMinutesHG45 & -0.0938 & 0.20789 & SixHoursHG45 & 0.0422 & 0.57274 \\
\hline FifteenMinutesHG85 & -0.0422 & 0.57273 & SixHoursHG85 & -0.0143 & 0.84986 \\
\hline
\end{tabular}

\subsubsection{Stationarity vs Nonstationarity Analysis}

Stationary and nonstationary models are constructed for the future precipitation data and compared with each other. First nonstationary models are compared among themselves and then nonstationary model with the best fit diagnostic values is compared with stationary models. AIC, BIC and NLL values of stationary models and their corresponding best fit nonstationary ones are presented in Table 4.6. The results of best fit nonstationary models spread among the various model trials. More than $60 \%$ of constructed nonstationary models reveal best fit results for the models in which location parameter is set to a function of Temperature and $\exp ($ Temperature), and scale parameter is set to a function of $\exp$ (Temperature). Generally, best fit nonstationary models provide lower diagnostic values (at least one of three evaluation criteria) and hence they are superior comparing to stationary models.

For every model and its corresponding RCP scenarios, mean and median of best fit nonstationary return level estimate results are compared with stationary model results for all storm durations and their percent changes of these values are given in Table 4.7. For 10 min, 15 min and 1-hour durations the models with RCP 4.5 produced increased (positive change) return levels (up to 6 percent) with nonstationarity whereas the models with RCP 8.5 yielded 
decreased (negative change) return levels (up to 4 percent). However, regardless of RCP scenarios almost all models (especially GFDL) released reduced (negative change) return levels with nonstationarity for 6-hour duration and such changes in return levels reached to 15 percent in maximum (based on median value). Magnitude of these changes increased with increasing return periods. The changes greater than 3 percent are highlighted in Table 4.7. GFDL and HG models with RCP 4.5 increased the return levels with nonstationarity particularly for $10 \mathrm{~min}, 15 \mathrm{~min}$ and 1-hour durations. The magnitude of future variations in extreme precipitation quantiles is dependent to the selection of GCMs and/or RCPs as it is also stated in Alam [79] who conducted the study of IDF curves analyses for Saskatoon, Canada, with possible climate change scenarios. Owing to semi-arid/arid climate conditions at the study location (Ankara province) Ankara is likely to encounter lower maximum precipitation depths at different frequencies in the future especially for the warmest condition (RCP 8.5) and longest duration (6-hour).

Table 4.6 - Diagnostic Values of Stationary and Best Fit Nonstationary Models of Projected Data

\begin{tabular}{|c|c|c|c|c|c|c|}
\hline \multirow{2}{*}{ Model } & \multicolumn{3}{|c|}{ Stationary } & \multicolumn{3}{|c|}{ Best Fit Nonstationary } \\
\hline & $\mathbf{N} \mathbf{L} \mathbf{L}$ & AIC & BIC & N L L & AIC & BIC \\
\hline TenMinMPI45 & 160.49 & 329.98 & 334.27 & 159.58 & 327.15 & 336.88 \\
\hline TenMinMPI85 & 132.92 & 271.84 & 279.13 & 128.45 & 264.91 & 274.63 \\
\hline TenMinGFDL45 & 124.99 & 255.97 & 263.26 & 123.57 & 255.15 & 267.87 \\
\hline TenMinGFDL85 & 2.65 & 11.31 & 18.60 & -1.81 & 6.38 & 18.53 \\
\hline TenMinHG45 & 181.79 & 369.57 & 376.86 & 180.24 & 368.47 & 378.20 \\
\hline TenMinHG85 & 43.77 & 93.53 & 100.83 & 43.21 & 94.42 & 104.15 \\
\hline FifteenMinMPI45 & 165.88 & 337.76 & 345.05 & 164.76 & 337.52 & 347.24 \\
\hline FifteenMinMPI85 & 169.16 & 344.31 & 351.61 & 166.22 & 340.43 & 350.16 \\
\hline FifteenMinGFDL45 & 151.40 & 308.81 & 316.10 & 149.05 & 306.10 & 315.83 \\
\hline FifteenMinGFDL85 & 33.81 & 73.61 & 80.91 & 31.63 & 71.25 & 80.98 \\
\hline FifteenMinHG45 & 203.40 & 412.81 & 420.10 & 201.64 & 411.29 & 421.013 \\
\hline FifteenMinHG85 & 74.74 & 155.48 & 162.78 & 74.03 & 156.06 & 165.78 \\
\hline \multirow{2}{*}{ Model } & \multicolumn{3}{|c|}{ Stationary } & \multicolumn{3}{|c|}{ Best Fit Nonstationary } \\
\hline & $\mathbf{N} \mathbf{L} \mathbf{L}$ & AIC & BIC & N L L & $\mathrm{AIC}$ & BIC \\
\hline OneHourMPI45 & 205.35 & 416.71 & 424.00 & 203.77 & 415.55 & 425.27 \\
\hline OneHourMPI85 & 258.91 & 523.82 & 531.11 & 252.66 & 513.33 & 523.05 \\
\hline OneHourGFDL45 & 235.48 & 476.96 & 484.25 & 234.06 & 476.13 & 485.85 \\
\hline OneHourGFDL85 & 142.67 & 291.34 & 298.63 & 138.44 & 286.87 & 299.03 \\
\hline OneHourHG45 & 246.33 & 498.66 & 505.95 & 244.51 & 497.02 & 506.74 \\
\hline OneHourHG85 & 181.81 & 369.61 & 376.91 & 179.66 & 367.33 & 377.05 \\
\hline
\end{tabular}


Investigation of the Effect of Climate Change on Extreme Precipitation: ...

Table 4.6 - Diagnostic Values of Stationary and Best Fit Nonstationary Models of Projected Data (continue)

\begin{tabular}{lcccccc}
\hline \multirow{2}{*}{ Model } & \multicolumn{3}{c}{ Stationary } & \multicolumn{3}{c}{ Best Fit Nonstationary } \\
\cline { 2 - 7 } & N L L & AIC & BIC & N L L & AIC & BIC \\
\hline SixHoursMPI45 & 303.82 & 613.65 & 620.94 & 302.85 & 613.71 & 623.43 \\
\hline SixHoursMPI85 & 292.30 & 590.61 & 597.90 & 281.20 & 572.41 & 584.56 \\
\hline SixHoursGFDL45 & 262.57 & 531.13 & 538.43 & 258.63 & 527.27 & 539.42 \\
\hline SixHoursGFDL85 & 261.93 & 529.86 & 537.15 & 252.61 & 515.21 & 527.37 \\
\hline SixHoursHG45 & 273.65 & 553.29 & 560.59 & 252.01 & 514.01 & 526.17 \\
\hline SixHoursHG85 & 264.12 & 534.24 & 541.53 & 264.08 & 536.17 & 545.89 \\
\hline
\end{tabular}

Table 4.7 - Nonstationary Model-Stationary Model Comparison - Mean and Median Return Value Change for 2-5-10-25-50-100-200 Years Return Period with Respect to Stationary Model - Projected Data for $10 \mathrm{~min}, 15 \mathrm{~min}, 1$ hour and 6 hour durations

\begin{tabular}{|c|c|c|c|c|c|c|c|c|c|c|c|c|}
\hline & 2 & 5 & 10 & 25 & 50 & 100 & 2 & 5 & 10 & 25 & 50 & 100 \\
\hline 10 Min Model & \multicolumn{6}{|c|}{ Mean Value Change } & \multicolumn{6}{|c|}{ Median Value Change } \\
\hline MPI45 & $0 \%$ & $0 \%$ & $0 \%$ & $0 \%$ & $0 \%$ & $0 \%$ & $0 \%$ & $0 \%$ & $0 \%$ & $0 \%$ & $0 \%$ & $0 \%$ \\
\hline MPI85 & $0 \%$ & $-1 \%$ & $-1 \%$ & $-2 \%$ & $-2 \%$ & $-2 \%$ & $1 \%$ & $0 \%$ & $-1 \%$ & $-1 \%$ & $-2 \%$ & $-2 \%$ \\
\hline GFDL45 & $-1 \%$ & $-1 \%$ & $0 \%$ & $0 \%$ & $1 \%$ & $1 \%$ & $1 \%$ & $1 \%$ & $1 \%$ & $1 \%$ & $2 \%$ & $2 \%$ \\
\hline GFDL85 & $1 \%$ & $0 \%$ & $0 \%$ & $-1 \%$ & $-1 \%$ & $-2 \%$ & $2 \%$ & $2 \%$ & $2 \%$ & $2 \%$ & $2 \%$ & $2 \%$ \\
\hline HG45 & $0 \%$ & $-1 \%$ & $0 \%$ & $1 \%$ & $2 \%$ & $2 \%$ & $0 \%$ & $-1 \%$ & $0 \%$ & $1 \%$ & $2 \%$ & $2 \%$ \\
\hline HG85 & $0 \%$ & $0 \%$ & $0 \%$ & $0 \%$ & $0 \%$ & $0 \%$ & $-1 \%$ & $-1 \%$ & $-1 \%$ & $-1 \%$ & $0 \%$ & $0 \%$ \\
\hline 15 Min Model & \multicolumn{6}{|c|}{ Mean Value Change } & \multicolumn{6}{|c|}{ Median Value Change } \\
\hline MPI45 & $0 \%$ & $0 \%$ & $0 \%$ & $0 \%$ & $1 \%$ & $2 \%$ & $0 \%$ & $0 \%$ & $0 \%$ & $1 \%$ & $1 \%$ & $2 \%$ \\
\hline MPI85 & $0 \%$ & $-1 \%$ & $-1 \%$ & $-2 \%$ & $-2 \%$ & $-2 \%$ & $1 \%$ & $0 \%$ & $-1 \%$ & $-1 \%$ & $-2 \%$ & $-2 \%$ \\
\hline GFDL45 & $-1 \%$ & $-1 \%$ & $-1 \%$ & $0 \%$ & $0 \%$ & $0 \%$ & $-1 \%$ & $-1 \%$ & $-1 \%$ & $0 \%$ & $0 \%$ & $0 \%$ \\
\hline GFDL85 & $0 \%$ & $0 \%$ & $-1 \%$ & $-1 \%$ & $-1 \%$ & $-1 \%$ & $0 \%$ & $0 \%$ & $0 \%$ & $0 \%$ & $-1 \%$ & $-1 \%$ \\
\hline HG45 & $-1 \%$ & $-1 \%$ & $0 \%$ & $2 \%$ & $3 \%$ & $5 \%$ & $-1 \%$ & $-1 \%$ & $0 \%$ & $2 \%$ & $3 \%$ & $5 \%$ \\
\hline HG85 & $0 \%$ & $0 \%$ & $0 \%$ & $0 \%$ & $0 \%$ & $0 \%$ & $-2 \%$ & $-1 \%$ & $-1 \%$ & $-1 \%$ & $-1 \%$ & $0 \%$ \\
\hline 1 Hour Model & \multicolumn{6}{|c|}{ Mean Value Change } & \multicolumn{6}{|c|}{ Median Value Change } \\
\hline MPI45 & $-1 \%$ & $-1 \%$ & $-1 \%$ & $-1 \%$ & $-2 \%$ & $-2 \%$ & $-1 \%$ & $-1 \%$ & $-1 \%$ & $-1 \%$ & $-2 \%$ & $-2 \%$ \\
\hline MPI85 & $0 \%$ & $-2 \%$ & $-2 \%$ & $-1 \%$ & $-1 \%$ & $0 \%$ & $1 \%$ & $-1 \%$ & $-2 \%$ & $-1 \%$ & $0 \%$ & $1 \%$ \\
\hline GFDL45 & $-1 \%$ & $0 \%$ & $0 \%$ & $1 \%$ & $2 \%$ & $3 \%$ & $-1 \%$ & $0 \%$ & $0 \%$ & $1 \%$ & $2 \%$ & $3 \%$ \\
\hline GFDL85 & $0 \%$ & $0 \%$ & $-1 \%$ & $-2 \%$ & $-3 \%$ & $-3 \%$ & $2 \%$ & $2 \%$ & $1 \%$ & $1 \%$ & $0 \%$ & $0 \%$ \\
\hline HG45 & $0 \%$ & $-1 \%$ & $-1 \%$ & $0 \%$ & $0 \%$ & $0 \%$ & $0 \%$ & $-1 \%$ & $-1 \%$ & $0 \%$ & $0 \%$ & $0 \%$ \\
\hline HG85 & $0 \%$ & $-1 \%$ & $-1 \%$ & $-1 \%$ & $-1 \%$ & $-1 \%$ & $-3 \%$ & $-3 \%$ & $-2 \%$ & $-2 \%$ & $-2 \%$ & $-2 \%$ \\
\hline 6 Hours Model & \multicolumn{6}{|c|}{ Mean Value Change } & \multicolumn{6}{|c|}{ Median Value Change } \\
\hline MPI45 & $0 \%$ & $-1 \%$ & $-1 \%$ & $-2 \%$ & $-2 \%$ & $-3 \%$ & $0 \%$ & $-1 \%$ & $-1 \%$ & $-2 \%$ & $-2 \%$ & $-3 \%$ \\
\hline MPI85 & $2 \%$ & $2 \%$ & $1 \%$ & $0 \%$ & $0 \%$ & $-1 \%$ & $2 \%$ & $3 \%$ & $3 \%$ & $3 \%$ & $3 \%$ & $2 \%$ \\
\hline GFDL45 & $1 \%$ & $0 \%$ & $-2 \%$ & $-5 \%$ & $-7 \%$ & $-10 \%$ & $1 \%$ & $-1 \%$ & $-3 \%$ & $-6 \%$ & $-9 \%$ & $-12 \%$ \\
\hline GFDL85 & $0 \%$ & $-2 \%$ & $-3 \%$ & $-5 \%$ & $-7 \%$ & $-9 \%$ & $1 \%$ & $0 \%$ & $-1 \%$ & $-3 \%$ & $-4 \%$ & $-5 \%$ \\
\hline HG45 & $0 \%$ & $-1 \%$ & $-3 \%$ & $-5 \%$ & $-7 \%$ & $-9 \%$ & $2 \%$ & $2 \%$ & $1 \%$ & $-1 \%$ & $-2 \%$ & $-4 \%$ \\
\hline HG85 & $0 \%$ & $0 \%$ & $0 \%$ & $0 \%$ & $0 \%$ & $0 \%$ & $0 \%$ & $0 \%$ & $0 \%$ & $0 \%$ & $0 \%$ & $0 \%$ \\
\hline
\end{tabular}


Further the average of stationary and nonstationary model-RCP combinations of each storm duration are computed. Stationary return level averages MPI, GFDL, HG models RCP 4.5 and 8.5 results and nonstationary return level means of MPI, GFDL, HG models RCP 4.5 and 8.5 results are compared. These results are given in Figure 4.5.

It can be concluded that on average nonstationary models produce mostly lower return levels for six-hour storm duration and closer return level values for the rest of the storm duration within the same RCP scenario. Moreover RCP 8.5 model averages for all storm durations exhibit smaller values when compared with the RCP 4.5 return level values however future projections can reveal different results for different regions. While it is found that stationary return level estimates for projections reveal higher values in this study, DeGaetano et al. [80] computed future precipitation recurrence probabilities for NY State to consider the future flood risk. The study reveals that at the end of the century, NYS will face a median change of between 20 and $30 \%$ increase in one-hundred-year recurrence interval precipitation amounts.

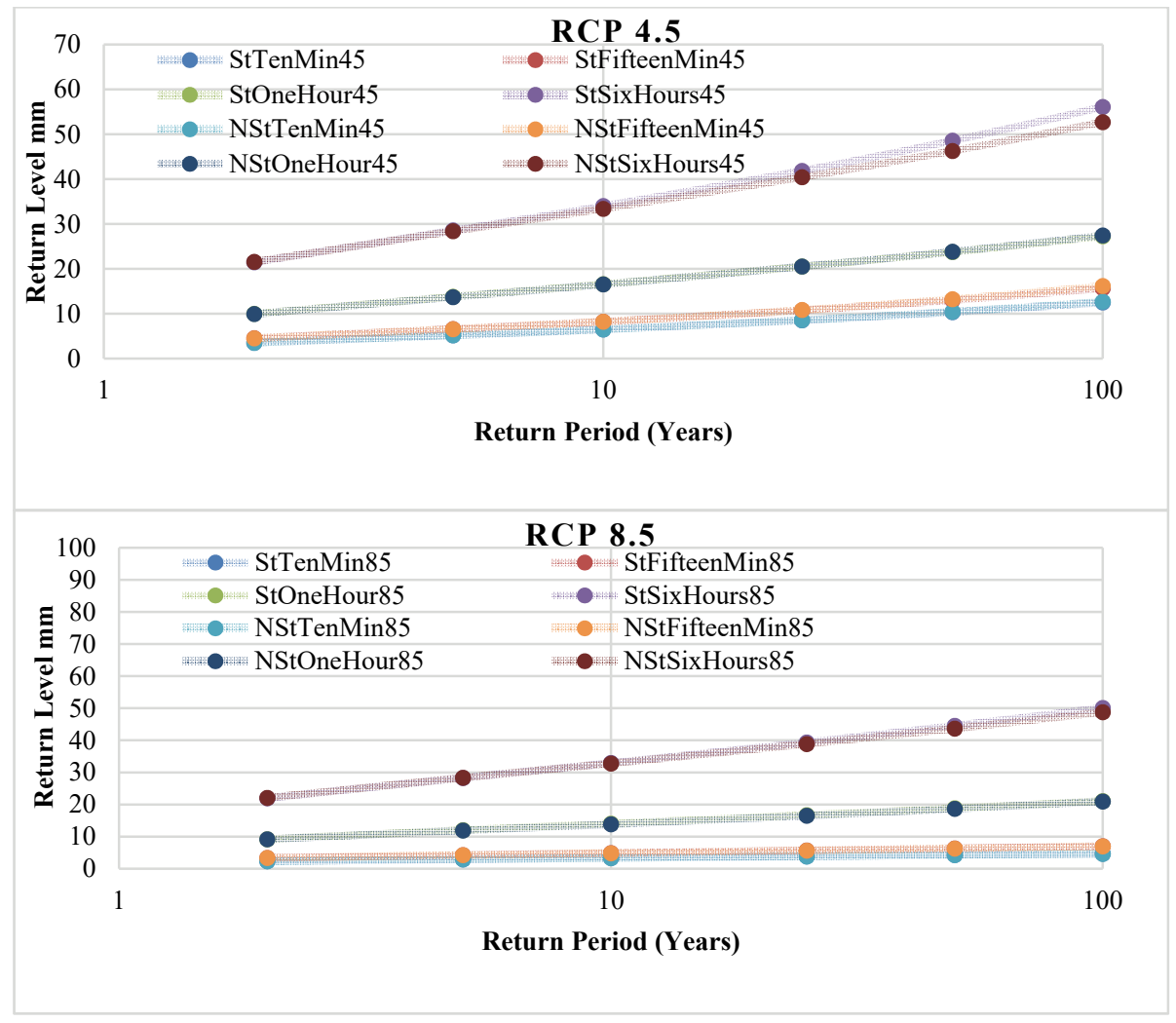

Figure 4.5 - Nonstationary Model-Stationary Model Comparison for Projected Data Average Values

Furthermore, observation and projection period return level results are also compared in a single plot to capture and illustrate the potential temporal change. Stationary and 
nonstationary return level plots of observed period, average stationary and nonstationary results of projected period and models that reveal the highest return level values among the model\&RCP combinations (HG 4.5 for 10 and 15 minutes; MPI 8.5 for 1 hour and MPI 4.5 for 6 hours) of storm durations (10 minutes, 15 minutes, 1 hour, 6 hours) are presented in the Figures 4.6.

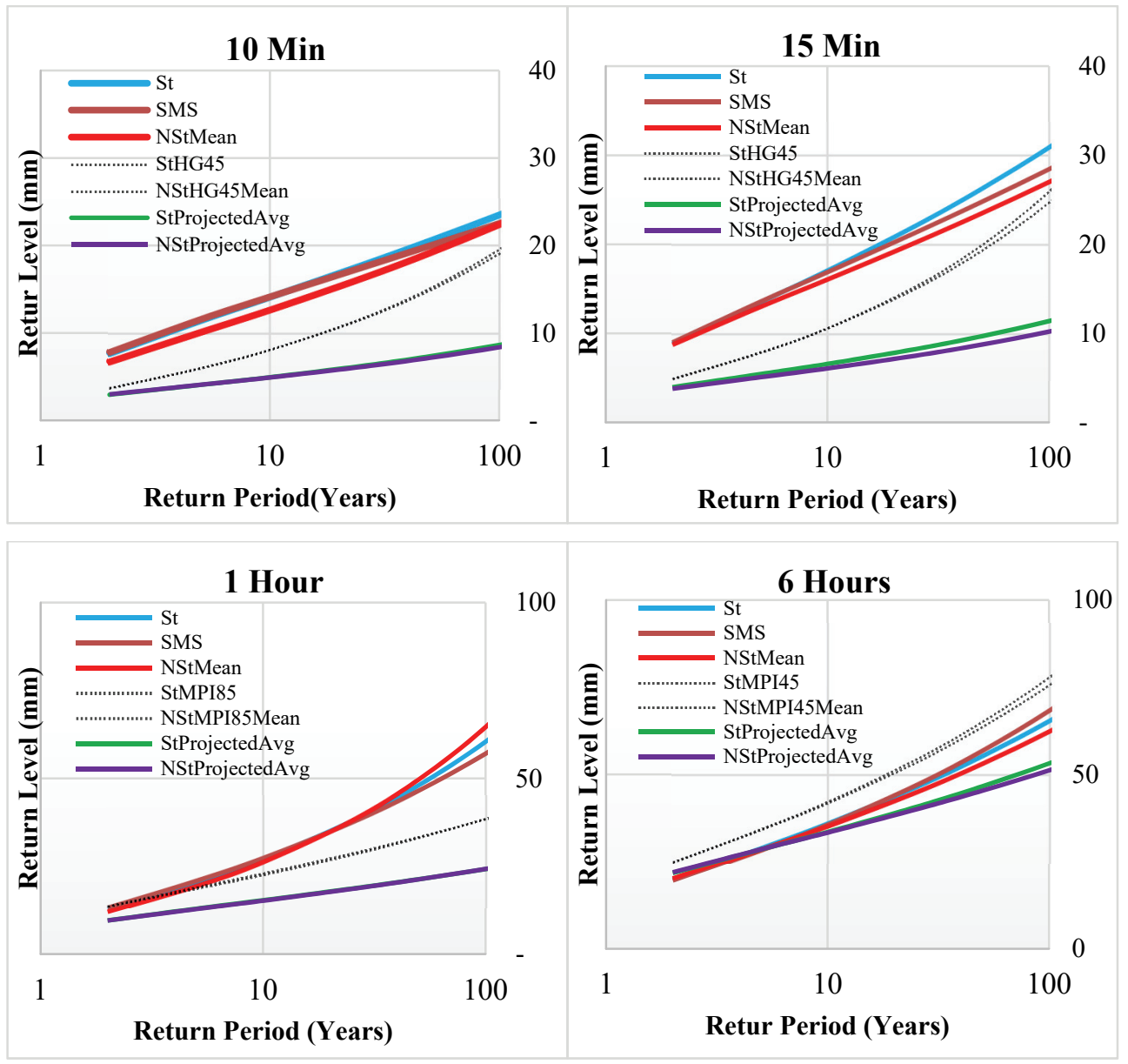

Figure 4.6 - Model Comparison - Observed Stationary and nonstationary, SMS, projected average stationary and nonstationary model results and model results with highest return level values of storm durations (10 minutes, 15 minutes, 1 hour, 6 hours)

For $10 \mathrm{~min}$ and $15 \mathrm{~min}$ storm durations in observed period, stationary return levels are higher than nonstationary levels while they are lower for 1-hour duration. In addition, for these storm durations all projected return levels with and without nonstationarity are lower than return levels in observed period. Discrepancies in return levels of observed and projected periods for these storms are significantly high which can be seen from the differences between 
average values of projected period and the observed period values. However, with 6-hr duration these differences in between two periods are somewhat reduced. Even return levels of MPI with RCP 4.5 exceeded return levels calculated in historical period. Nevertheless, the maximum precipitation depths by the end of century will likely to occur with reduced magnitude comparing to the current time. In other words, the same precipitation depth in the future (by the end of century) can occur with longer return periods. With higher recurrence time and shorter storm duration this feature is more pronounced and therefore the severity of the extreme precipitation will probably be reduced in the future. Nonstationarity effect further decreases the return levels particularly for return periods greater than 10 year but it shows tendency to increase precipitation depths for sub-hourly durations even with return periods lower than 10 year. This aspect of the nonstationarity is effective in both periods.

In this study a general decrease in extreme rainfall return levels detected for the Ankara. However, for all return periods, six hours storm duration projected data driven model results do not fit the general trend. On the other hand, there are uncertainty caused by different aspects of the data and lack of practice as stated in the literature which complicate the analyses especially for future conditions. For instance Fadhel et al. [81] show that the use of different reference periods for the bias correction of RCM raise the uncertainty in the future IDF curves and emphasize the effect of the reference period on future climate projections, Kara [82] concluded that all RCMs may underestimate precipitation and Simonovic et al. [83] found that a reduction in extreme precipitation in central regions of Canada and increases in other regions based on CanESM2 results but also mentioned the GCM based uncertainty and the difference between ensemble and single model results. Moreover Arnbjerg Nielsen et al., [84] state the lack of understanding of how to quantify the impacts of climate change and the insufficiency of long-term rainfall statistics so the understanding of consequences of climate change stays limited. Haktanır and Çıtakoğlu [34] indicated that Intensity-DurationFrequency (IDF) curves can be computed in the conventional way for Turkey which supports the findings of this study. Moreover, the future results are in line with the observed trends which indicated significant decreasing trend. On the other hand, Almazroui et al. [85] stated an average 5\% increase in the rainfall intensity for semi-arid region of Turkey while Şen and Aksu [86] divided two equal halves the 7 meteorological station data of annual maximum series in İstanbul and indicated an increase of up to $30 \%$ rainfall intensity for the second period. Nevertheless, the difference between highest model results and average results for the projected data in this study indicates the unavoidable uncertainty.

\section{SUMMARY AND CONCLUSIONS}

In the present study, intensity-duration-frequency analysis of precipitation for the reference (1950-2015) and the future (2015-2098) conditions, which enables us to incorporate climate change and variability into the design and management of storm water drainage systems, is performed and discussed under stationary and non-stationary conditions for the capital and semi-arid climate of Ankara province in Turkey. The precipitation records of SMS of Turkey for observation period and the results of regional climate model simulations based on the HadGEM2-ES, MPI-ESM-MR and GFDL-ESM2M models with RCP4.5 and RCP8.5 scenarios for future periods have been used. Daily future precipitation projections are disaggregated to 5 minute and used for the future period analysis. The GEV frequency models for stationary and nonstationary cases during observed and projected periods are developed. 
The maximum precipitation depths of all storm durations showed statistically significant decreasing trends during observed period while the models with RCP 8.5 released significant decreasing trends but the models with RCP 4.5 produced significantly increasing trends for all storm durations in projected period. Depending on the choice of emission scenarios the direction of the trend line changes from current to the future period. With more optimistic scenario (RCP 4.5) the severity of wetness increases in the future, however it is reduced and aligned with observed period when pessimistic scenario (RCP 8.5) is used. The statistical significance in precipitation change over time also inferred the existence of unavoidable nonstationarity. The stationary GEV models are capable of fitting the extreme precipitation time series of all storm durations, but the non-stationary GEV models showed advantage over the stationary models according to the diagnostic tests and values. Nonstationary model results exhibited smaller return level values with respect to stationary model results of each storm duration for the observed period. These changes reached to $15 \%$ especially for $10-15$ min duration and 10-25 years return periods. These duration and frequencies are mostly considered in design of urban water drainage systems. Hence, the usage of nonstationarity approach becomes critical in application studies. Design magnitudes were lowered so that current structures do not consider nonstationarity would be overdesigned, however they will be safe for any failure. Similar reductions in return levels with nonstationarity were also obtained by models with RCP 8.5 in projected period. However, the nonstationarity models with RCP 4.5 increased the return levels in future. The negative effect of nonstationarity was the greatest for 6-hour duration regardless of any emission scenario and model.

In addition, return level values that are derived from observed data are greater than those from projected data almost for all storm duration and return period for 10-15 minutes and 16-hour storm duration. As the duration of storms increases projected return levels get closer to observed return levels. Future extreme precipitation depths for sub hourly storm durations are far lower than those in observed period. Therefore, the capacity of current operational storm drainage systems that were designed under stationarity will be safe enough and not create any operational difficulties in future based on the three model results used in this study. On the other hand, future projections, downscaling methods, disaggregation techniques host uncertainties that must be remembered in evaluation of the results.

Nevertheless, it should be noted that the differences in return level estimates of models support the need to update the current design parameters such as return level, return period with the most recent data and approaches. The differences also reveal the need to conduct analysis using future climate data.

\section{Acknowledgement}

Based on the article, two presentations were published at the 3rd International Electronic Conference on Water Sciences (ECWS-3) which was held online, promoted by the open access journal Water http://www.mdpi.com/journal/water; one presentation is presented and one full-text is published at 10th National Hydrology Congress, Muğla Sitkı Koçman University, The presentations that are published at ECWS-3 can be found at:

https://sciforum.net/paper/view/conference/5807

https://sciforum.net/paper/view/conference/5808 


\section{References}

[1] IPCC, (2013). Climate change 2013. The Physical Science Basis. Contribution of Working Group I to the Fifth Assessment Report of the Intergovernmental Panel on Climate Change.

[2] IPCC, (2014a). Climate change 2014. Impacts, Adaptation, and Vulnerability. Part A: Global and Sectoral Aspects. Contribution of Working Group II to the Fifth Assessment Report of the Intergovernmental Panel on Climate Change.

[3] IPCC, (2014b). Climate change 2014. Synthesis Report. Contribution of Working Groups I, II and III to the Fifth Assessment Report of the Intergovernmental Panel on Climate Change.

[4] Osborn, T. J., Gosling, S., Wallace, C., \& Dorling, S. (2015). The Water Cycle in a Changing Climate. 7th World Water Forum. Faircount Media Group, London, 14-19.

[5] Zhou, Q., Arnbjerg-Nielsen, K., Mikkelsen, P. S., Nielsen, S. B., \& Halsnæs, K. (2012). Urban drainage design and climate change adaptation decision making. Kgs. Lyngby: DTU Environment

[6] Papagiannaki, K., Lagouvardos, K., Kotroni, V., \& Bezes, A. (2015). Flash flood occurrence and relation to the rainfall hazard in a highly urbanized area, Nat. Hazards Earth Syst. Sci., 15, 1859-1871

[7] Willems, P. "Revision of Urban Drainage Design Rules after Assessment of Climate Change Impacts on Precipitation Extremes at Uccle, Belgium.” Journal of Hydrology, vol. 496, 2013, pp. 166-177., doi:10.1016/j.jhydrol.2013.05.037.

[8] Liew, S. C., Raghavan, S. V., \& Liong, S.Y. (2014). How to construct future IDF curves, under changing climate, for sites with scarce rainfall records?. Hydrol. Process., 28, 3276-3287. doi:10.1002/hyp.9839

[9] Pohl, B., Macron, C., \& Monerie, P-A. (2017). Fewer rainy days and more extreme rainfall by the end of the century in Southern Africa. Scientific Reports, 7, 46466. doi: $10.1038 /$ srep46466

[10] Seneviratne, S. I., Nicholls, N., Easterling, D., Goodess, C. M., Kanae, S., \& Kossin, J. (2012). Changes in climate extremes and their impacts on the natural physical environment. Cambridge University Press, Cambridge, UK, and New York, NY.

[11] Ozturk, T., Turp, M. T., Türkeş, M., \& Kurnaz, M. L. (2018). Future projections of temperature and precipitation climatology for CORDEX-MENA domain using RegCM4.4. Atmospheric Research, 206, 87-107. doi:10.1016/j.atmosres.2018.02.00

[12] Kusunoki, S., (2017). Future changes in global precipitation projected by the atmospheric model MRI-AGCM3.2H with a 60-km size. Atmosphere, 8, 93

[13] Buttstadt, M., \& Schneider, C. (2014). Climate change signal of future climate projections for Aachen, Germany, in terms of temperature and precipitation. Mareike, 68(2), 71-83.

[14] Meld, (2013). Climate change adaptation in Norway Meld. St. 33 (2012-2013) Report to the Storting (white paper) Recommendation of 7. May 2013 from the Ministry of the Environment, approved in the Council of State the same day. (White paper from the Stoltenberg II Government). 
[15] IPCC, (2012). Managing the risks of extreme events and disasters to advance climate change adaptation. A Special Report of Working Groups I and II of the Intergovernmental Panel on Climate Change.

[16] Kundzewicz, Z. W., Kanae, S., Seneviratne, S. I., Handmer, J., Nicholls, N., Peduzzi, P., Mechler, R., Bouwer, L. M., Arnell, N., Mach, K., Muir-Wood, R. G., Robert, B., Wolfgang, K., Gerardo, B., Yasushi, H., Kiyoshi, T., \& Boris, S. (2014). Flood risk and climate change: global and regional perspectives. Hydrological Sciences Journal, 59(1), 1-28. doi: 10.1080/02626667.2013.857411

[17] Li, J., Johnson, F., Evans, J., \& Sharma, A. (2017). A comparison of methods to estimate future sub-daily design rainfall. Advances in Water Resources, 110. 10.1016/j.advwatres.2017.10.020.

[18] Hettiarachchi, S., Wasko, C., \& Sharma, A. (2018). Increase in flood risk resulting from climate change in a developed urban watershed - the role of storm temporal patterns, Hydrol. Earth Syst. 22, 2041-2056.

[19] Cheng, L., \& AghaKouchak, A. (2014). Nonstationary precipitation intensity-durationfrequency curves for infrastructure design in a changing climate. Sci. Rep. 4, 7093. doi:10.1038/srep07093

[20] Sarhadi, A., \& Soulis, E. D. (2017). Time-varying extreme rainfallintensity-durationfrequency curvesin a changing climate, Geophys. Res.Lett., 44. doi:10.1002/2016GL072201

[21] Peck, A., Prodanovic, P., \& Simonovic, S. P. (2012). Rainfall intensity duration frequency curves under climate change: city of London, Ontario, Canada. Can. Water Res. J., 37(3), 177-189. http://dx.doi.org/10.4296/cwrj2011-935

[22] Hosseinzadehtalaei, P., Tabari, H., \& Willems, P. (2017). Precipitation intensityduration-frequency curves for central Belgium with an ensemble of Eurocordex simulations, and associated uncertainties. Atmospheric Research, 200, 1-12. doi:10.1016/j.atmosres.2017.09.015

[23] Willems, P., Olsson, J., Arnbjerg-Nielsen, K., Beecham, S., Pathirana, A., Gregersen, I.B., Madsen, H., Nguyen, V.T.V. (2012). Impacts of climate change on rainfall extremes and urban drainage. IWA Publishing, London, UK.

[24] Yuan, X.-C., Wei, Y.-M., Wang, B., and Mi, Z. (2017). Risk management of extreme events under climate change, J. Clean. Prod., 166,1169-1174, https://doi.org/10.1016/j.jclepro.2017.07.209, 2017

[25] Yoon, J. H., Wang, S. Y., Gillies, R. R., Kravitz, B., Hipps, L., \& Rasch, P. J. (2015). Increasing water cycle extremes in California and relation to ENSO cycle under global warming. Nat. Commun, 6, 8657 doi: 10.1038/ncomms9657

[26] Simonovic, S. P. (2012). Floods in a changing climate: Risk management, 194. Cambridge: Cambridge University Pres

[27] Huntington, T. G. (2006). Evidence for intensification of the global water cycle: review $\begin{array}{llll}\text { and } & \text { Jynthesis. }\end{array}$ http://dx.doi.org/10.1016/j.jhydrol.2005.07.003 
[28] Abdellatif, M., Atherton, W., \& Alkhaddar, R. (2013). Application of the stochastic model for temporal rainfall disaggregation for hydrological studies in North Western England. Journal of Hydroinformatics, 15(2), 555-567.

[29] Harisaweni, Z., \& Fadhilah, Y. (2016). The use of BLRP model for disaggregating daily rainfall affected by monsoon in Peninsular Malaysia. Sains Malaysiana, 45 (1). 87-97.

[30] Kossieris, P., Makropoulos, C., Onof, C., \& Koutsoyiannis, D. (2016b). HyetosMinute, A package for temporal stochastic simulation of rainfall at fine time scales, Version 2.0.

[31] SMS, (2020). Republic of Turkey, the ministry of forestry and water affairs, state meteorological service, State of the Climate in Turkey in 2019, January 2020

[32] Sensoy, S., Türkoğlu, N., Akçakaya, A., Ulupınar, Y., Ekici, M., Demircan, M., Atay, H., Tüvan, A., \& Demirbaş, H. (2013). Trends in Turkey climate indices from 1960 to 2010, 6th Atmospheric Science Symposium, 24 - 26 April 2013, ITU, Istanbul, Turkey.

[33] Danandeh Mehr, A. and Kahya, E. (2016). Climate change impacts on catchment-scale extreme rainfall variability: Case Study of Rize Province, Turkey. Journal of Hydrologic Engineering, 10.1061/(ASCE)HE.1943-5584.0001477, 05016037.

[34] Haktanir, T., \& Citakoglu, H. (2014). Trend, independence, stationarity, and homogeneity tests on maximum rainfall series of standard durations recorded in Turkey. Journal of Hydrologic Engineering, 19, 9. DOI: 10.1061/(ASCE)HE.19435584.0000973.

[35] Yilmaz, A. G. (2015). The effects of climate change on historical and future extreme rainfall in Antalya, Turkey. Hydrological Sciences Journal, 60(12), 2148-2162. doi: 10.1080/02626667.2014.945455

[36] Tayanç, M., İm, U., Doğruel, M., \& Karaca, M. (2009). Climate change in Turkey for the last half century. Climatic Change, 94, 483-502.

[37] Turunçoğlu, U. U., Türkeş, M., Bozkurt, D., Önol, B., Şen, Ö. L., \& Dalfes, H. N. (2018). The Soils of Turkey. World Soils Book Series. Springer, Cham.

[38] WRP, (2016). Republic of Turkey, the ministry of forestry and water affairs, general directorate of water management. Climate Change Impacts On Water Resources Project.

[39] Aziz, R. (2018). Impacts Of Climate Nonstationarities On Hydroclimatological Variables In Turkey, PhD. Dissertation. Middle East Technical University

[40] Aziz, R.,Yucel, I., Yozgatligil, C. (2020). Nonstationarity impacts on frequency analysis of yearly and seasonal extreme temperature in Turkey. Atmospheric Research, 238, doi.org/10.1016/j.atmosres.2020.104875

[41] Maraun, D. (2016). Bias correcting climate change simulations - a critical review. Curr Clim Change Rep 2(4):211-220. doi: 10.1007/s40641-016-0050-X

[42] Willkofer, F.; Schmid, F.J.; Komischke, H.; Korck, J.; Braun, M.; Ludwig, R. The impact of bias correcting regional climate model results on hydrological indicators for Bavarian catchments. J. Hydrol. Reg. Stud. 2018, 19, 25-41 
[43] Demircan, M , Gürkan, H, Eskioğlu, O , Arabacı, H , Coşkun, M . (2017). Climate Change Projections for Turkey: Three Models and Two Scenarios . Turkish Journal of Water Science and Management , 1 (1) , 22-43 . DOI: 10.31807/tjwsm.297183

[44] Kossieris, P., Makropoulos, C., Onof, C., \& Koutsoyiannis, D. (2016a). A rainfall disaggregation scheme for sub-hourly time scales: Coupling a Bartlett-Lewis based model with adjusting procedures, Journal of Hydrology, 556, 980-992.

[45] Kaczmarska, J. M., Isham, V. S., \& Northrop, P. (2015). Local generalised method of moments: an application to point process-based rainfall models. Environmetrics, 26, 312-325. doi: 10.1002/env.2338

[46] Ritschel, C., Ulbrich, U., Névir, P., \& Rust, H. W. (2017). Precipitation extremes on multiple timescales - Bartlett-Lewis rectangular pulse model and intensity-durationfrequency curves. Hydrology and Earth System Sciences, 21(12), 6501.

[47] Yılmaz, E. (2013). Ankara Şehrinde Isı Adası Oluşumu. (Doktora Tezi), Ankara Üniversitesi, Sosyal Bilimler Enstitüsü, Ankara.

[48] Governorate of Ankara, (2018). Geography and demographics. [online] Available at: http://eng.ankara.gov.tr/geography-and-demographics. [Accessed 01 June 2018].

[49] Batuman, B. (2013). City profile: Ankara. Cities, 31. 578-590. 10.1016/j.cities.2012.05.016

[50] Sensoy, S., Turkoglu, N., Cicek I., Demircan, M., Arabacı, H., Bölük, E., 2014, Urbanization Effect on Trends of Extreme Temperature Indices in Ankara, 7th Atmospheric Science Symposium, 28-30 April 2015, İstanbul

[51] Çiçek, I., \& Turkoglu, N.. (2005). Urban effects on precipitation in Ankara. Atmósfera, 18(3), 173-187.

[52] Kossieris, P., Koutsoyiannis, D., Onof, C., Tyralis, H., \& Efstratiadis, A. (2012). HyetosR: An R package for temporal stochastic simulation of rainfall at fine time scales. European Geosciences Union General Assembly 2012, Geophysical Research Abstracts, Vol. 14, Vienna, 11718, European Geosciences Union.

[53] Rodriguez-Iturbe, I., Cox, D. R., \& Isham, V. (1987a). Some models for rainfall based on stochastic point processes. Proceedings of the Royal Society, 410, 269-288.

[54] Rodriguez-Iturbe, I., Febres de Power, B., \& Valdes, J. B. (1987b). Rectangular pulses point process models for rainfall: analysis of empirical data. Journal of Geophysical Research, 92, 9645-9656.

[55] Villani, V., Di Serafino, D., Guido, R., \& Mercogliano, P. (2016). Stochastic models for the disaggregation of precipitation time series on sub-daily scale: identification of parameters by global optimization. CMCC Research Paper No. RP0256. http://dx.doi.org/10.2139/ssrn.2602889

[56] Lu, Y., \& Qin, X. S. (2012). Comparison of stochastic point process models of rainfall in Singapore. Proceedings of 2012 International Conference of World Academy on Science, Engineering and Technology (WASET), 68, 1234-1238.

[57] Rozos, E., Efstratiadis, A., Nalbantis, I., \& Koutsoyiannis, D. (2004).Calibration of a semi-distributed model for conjunctive simulation of surface and groundwater flows, Hydrological Sciences Journal, 49(5), 819-842. 
[58] Efstratiadis, A., and D. Koutsoyiannis, An evolutionary annealing-simplex algorithm for global optimisation of water resource systems, (2002). Proceedings of the Fifth International Conference on Hydroinformatics, Cardiff, UK, 1423-1428, International Water Association, (http: //itia.ntua.gr/el/docinfo/524/)

[59] Yilmaz, A. G., \& Perera, B. J. C. (2014). Extreme rainfall non-stationarity investigation and intensity-frequency-duration relationship. J. Hydrol. Eng. 19, 1160-1172. doi: 10.1061/(ASCE)HE.1943-5584.0000878

[60] Mann, H. B. (1945). Non-parametric tests against trend, Econometrica, 13,163-171.

[61] Kendall, M. G. (1975). Rank correlation methods, 4th edition, Charles Griffin, London.

[62] Gilbert, R. O. (1987). Statistical Methods for Environmental Pollution Monitoring. Wiley, NY.

[63] Onyutha, C., Tabari, H., Taye, M. T., Nyandwaro, G. N., \& Willems, P. (2015). Analyses of rainfall trends in the Nile River basin. J Hydro Environ Res, 13, 36-51.

[64] Yucel, I., Güventürk, A. and Sen, O. L. (2014), Climate change impacts on snowmelt runoff for mountainous transboundary basins in eastern Turkey. Int. J. Climatol., 35: 215-228. doi:10.1002/joc.3974

[65] Umbricht, A., Fukutome, S., Liniger, M. A., Frei, C., \& Appenzeller, C. (2013). Seasonal variation of daily extreme precipitation in Switzerland. Scientific Report. MeteoSwiss, 97, 122.

[66] Collet L., Beevers, L., \& Prudhomme C. (2017). Assessing the impact of climate change and extreme value uncertainty to extreme flows across Great Britain. Water, $9(2), 103$.

[67] Coles, S. G., \& Sparks, R. S. J. (2006). Extreme value methods for modelling historical series of large volcanic magnitudes. Chapter 5, Statistics in Volcanology.

[68] Wang, J., You, S., Wu, Y., Zhang, Y., \& Bin, S. (2016). A method of selecting the block size of bmm for estimating extreme loads in engineering vehicles. Mathematical Problems in Engineering. 1-9. 10.1155/2016/6372197.

[69] Cai, Y., \& Hames, D. (2010). Minimum sample size determination for generalized extreme value distribution,communications in statistics. Simulation and Computation, 40(1), 87-98. doi: 10.1080/03610918.2010.530368

[70] Coles, S. (2001). An Introduction to Statistical Modeling of Extreme Values, Springer, London.

[71] Gilleland, E., \& Katz, R. (2016). extRemes 2.0: An Extreme Value Analysis Package in R. Journal of Statistical Software, 72(8), 1-39. doi: 10.18637/jss.v072.i08

[72] Bayazit, M. (2015). Nonstationarity of hydrological records and recent trends in trend analysis: A State-of-the-art Review. Environmental Processes, 2, 527-542.

[73] Pohlert T. (2016). Non-Parametric Trend Tests and Change-Point Detection. R package Version 0.2.0.

[74] Gül, G., Aşıkoğlu, Ö., Gül, A., Gülçem, Y. F., \& Benzeden, E. (2014). Nonstationarity in flood time series. Journal of Hydrologic Engineering, 19, 1349-1360 
[75] Šraj, M., Viglione, A., Parajka, J., \& Blöschl, G. (2016). The influence of nonstationarity in extreme hydrological events on flood frequency estimation. Journal of Hydrology and Hydromechanics, 64, 426-437

[76] Cheng, L. (2014). Frameworks for univariate and multivariate non-stationary analysis of climatic extremes, PhD. Dissertation, UC Irvine.

[77] Wang, Y., \& Liu, Q. (2006). Comparison of Akaike information criterion (AIC) and Bayesian information criterion (BIC) in selection of stock-recruitment relationships. Fish. Res. 77, 220-225.

[78] Sienz, F., Schneidereit, A., Blender, R., Fraedrich, K., \& Lunkeit, F. (2010). Extreme value statistics for North Atlantic cyclones. Tellus A, 62(4), 347-360.

[79] Alam, S. (2014). Construction of the intensity-duration-frequency (idf) curves under climate change. Master of Science, University of Saskatchewan.

[80] DeGaetano, A. T., \& Castellano, C. M. (2017). Future projections of extreme precipitation intensity-duration-frequency curves for climate adaptation planning in New York State. Climate Services, 5, 23-35.

[81] Fadhel, S., Rico-Ramirez, M. A., \& Han, D. (2017). Uncertainty of intensity durationfrequency (IDF) curves due to varied climate baseline periods. Journal of Hydrology, 547, 600-612.

[82] Kara, F. (2014). Effects of climate change on water resources in Omerlı basin. PhD. Dissertation. Middle East Technical University

[83] Simonovic, S. P., Schardong, A., \& Sandink, D. (2017). Mapping extreme rainfall statistics for canada under climate change using updated intensity-duration-frequency curves. ASCE Journal of Water Resources Planning and Management, 143(3), 04016078-1 -04016078-12.

[84] Arnbjerg-Nielsen, K., Willems, P., Olsson, J., Beecham, S., Pathirana, A., Gregersen, I. B., \& Nguyen, V-T. V. (2013). Impacts of climate change on rainfall extremes and urban drainage systems: A review. Water Science and Technology, 68(1), 16-28. Doi: 10.2166/wst.2013.251.

[85] Almazroui, M., Şen, Z., Mohorji, A.M. et al. Impacts of Climate Change on Water Engineering Structures in Arid Regions: Case Studies in Turkey and Saudi Arabia. Earth Syst Environ 3, 43-57 (2019). https://doi.org/10.1007/s41748-018-0082-6

[86] Şen, K, Aksu, H . (2021). İstanbul İçin Standart Süreli Gözlenen En Büyük Yağışların Eğilimleri. Teknik Dergi , 32 (1) , 1-2 . DOI: 10.18400/tekderg.647558 